Portland State University

PDXScholar

$1-1-2011$

\title{
Black/White Health Disparities in the U.S. The Effect of Education over the Life-Course
}

Elizabeth Melissa Withers

Portland State University

Follow this and additional works at: https://pdxscholar.library.pdx.edu/open_access_etds Let us know how access to this document benefits you.

\section{Recommended Citation}

Withers, Elizabeth Melissa, "Black/White Health Disparities in the U.S. The Effect of Education over the Life-Course" (2011). Dissertations and Theses. Paper 42.

https://doi.org/10.15760/etd.42

This Thesis is brought to you for free and open access. It has been accepted for inclusion in Dissertations and Theses by an authorized administrator of PDXScholar. Please contact us if we can make this document more accessible: pdxscholar@pdx.edu. 
Black/White Health Disparities in the U.S.

The Effect of Education over the Life-Course

by

Elizabeth Melissa Withers

A thesis submitted in partial fulfillment of the requirements for the degree of

\author{
Master of Science \\ in \\ Sociology
}

Thesis Committee:

Matthew Carlson, Chair

Hyeyoung Woo

Margaret Everett

Portland State University

2011 


\begin{abstract}
In the United States there exists a clear and disconcerting racial disparity in the distribution of good health, which can be seen in differential levels of morbidity and mortality affecting blacks and whites. Previous research has examined the role of SES in shaping racial health disparities and recent studies have looked specifically at the effect of education on health to explain the racial disparity in health. Higher levels of education are robustly associated with good overall health for both blacks and whites and this association has been examined over the life-course. This research explores racial differences in the effect of education on health in general as well as over the life-course. Specifically, this paper examines race differences in the effects of education on health over the life-course.

Pooled data from the National Health Interview Survey were analyzed using multivariate logistic regression to estimate the effects of race, education and age on health. The results of these analyses indicate that blacks receive lower education returns on their health than whites. The effect of education on health was shown to grow in the beginning of the life-course and diminish at the end of the life course in accordance with the mortality-as-leveler hypothesis. The black white health disparity was shown to grow over the life-course among the highly educated, whereas the disparity was consistent over the life-course for the poorly educated.
\end{abstract}




\section{TABLE OF CONTENTS}

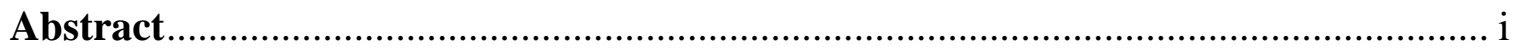

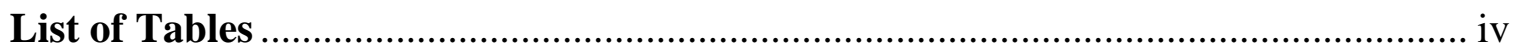

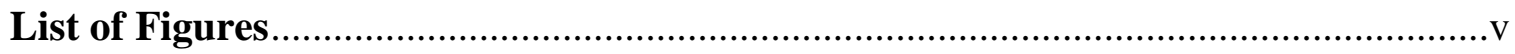

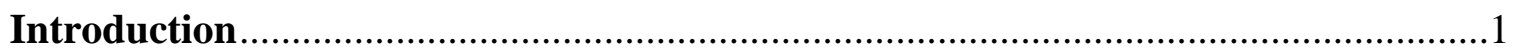

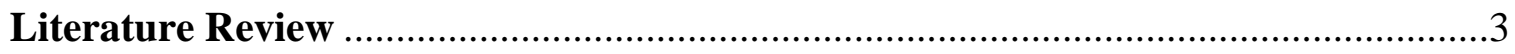

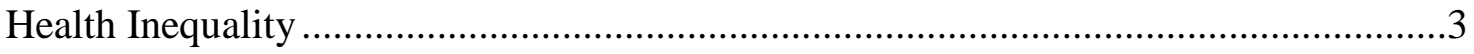

Racial Health Inequalities .....................................................................................

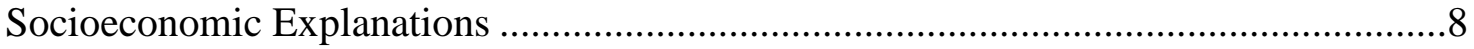

The Effect of Education on Health...........................................................................10

Health Disparities and the Life-Course …………….............................................15

Double Jeopardy Hypothesis: Racial Health Disparities Grow ……………………....15

Cumulative Advantage Hypothesis: Education-Health Disparities Grow ..................16

Age-as-Leveler Hypothesis: Racial Health Disparities Diminish ................................17

Age-as-Leveler Hypothesis: Education-Health Disparities Diminish..........................17

Mortality-as-Leveler Hypothesis: Racial and Education-Health Disparities Grow and

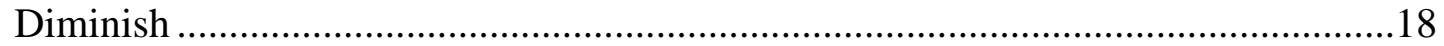

Research Questions and Hypotheses........................................................................20

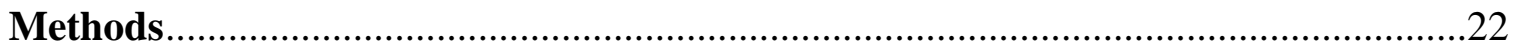

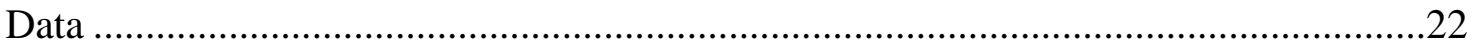

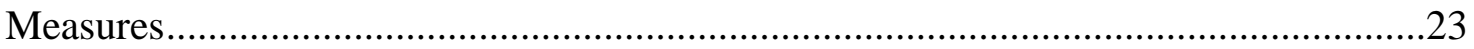

Dependent Variable …………………………………….................................23

Independent Variables .....................................................................................24

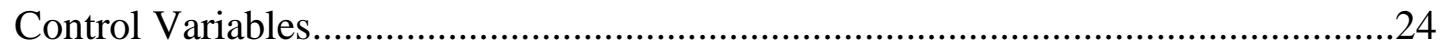




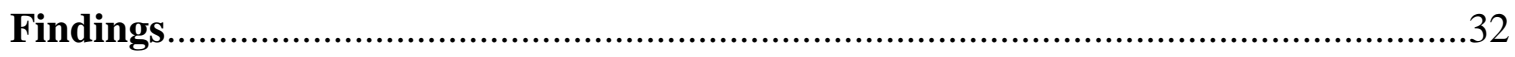

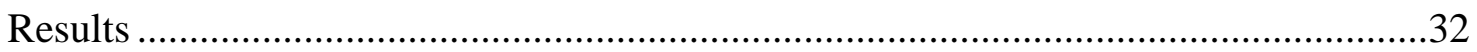

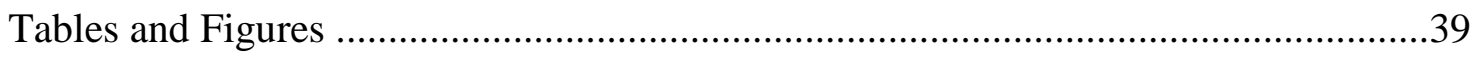

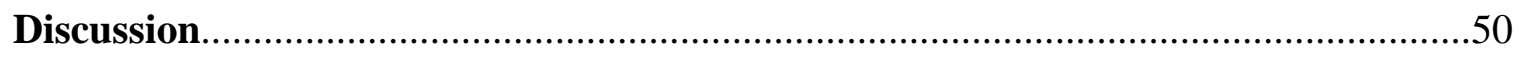

Racial Differences in the Effect of Education on Health .......................................50

Education-Health Disparity and the Life-Course ...............................................51

Racial Differences in the Effect of Education over the Life-Course ..........................52

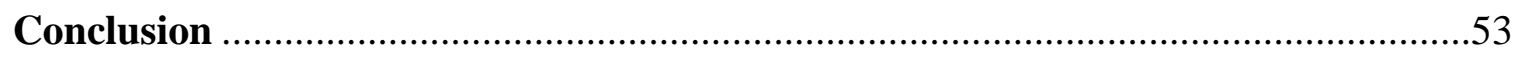

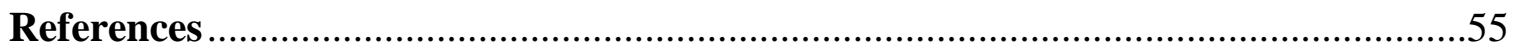




\section{LIST OF TABLES}

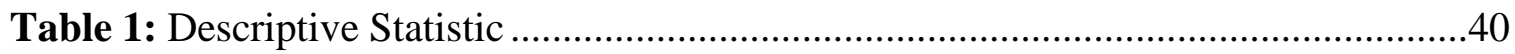

Table 2: Logistic Regression Measuring the Effects of Education on Health across Race

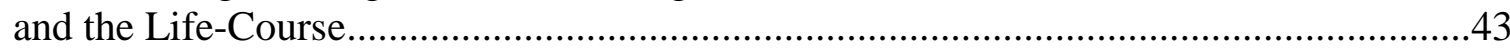




\section{LIST OF FigURES}

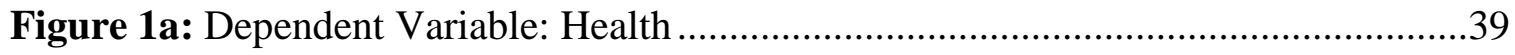

Figure 1b. Dependent Variable: Health recoded as dichotomous variable.......................39

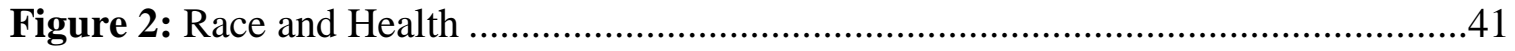

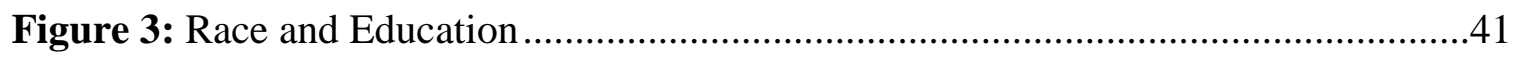

Figure 4: Racial Differences in Health by Level of Education....................................42

Figure 5: Racial Differences in Level of Education by Age..........................................42

Figure 6: Model 3: Racial Differences in the Effect of Education on Health .................44

Figure 7: Model 4: Racial Differences in the Effect of Age on Health ..........................45

Figure 8a: Model 5: Education-Health Disparity over the Life-Course: Whites ............46

Figure 8b: Model 5: Education-Health Disparity over the Life-Course: Blacks.............47

Figure 9a: Model 5: The Effect of Education on Health over the Life-Course for Low

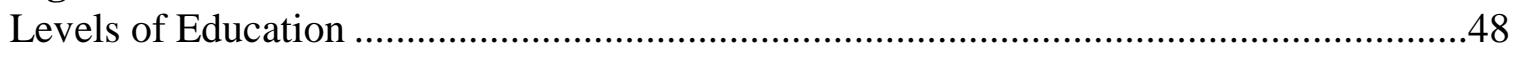

Figure 9b: Model 5: The Effect of Education on Health over the Life-Course for High

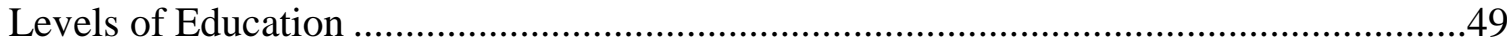




\section{INTRODUCTION}

The disparity in health between black and white Americans is one of the most devastating consequences of racism in the United States. Black Americans have been shown to have the highest mortality rate (NCHS, 2010) and infant mortality rate (Mead, 2008) in the United States. Black Americans are also more likely to rate their health poorly (Ferraro and Farmer and Wybraniac, 1997) and to suffer from physical limitations (Mead, 2008). Black/white health inequalities are immense and persistent and have received a lot of attention by researchers interested in both documenting and explaining the disparity. Many of these studies regarding racial health disparities have explained the relationship in terms of racial differences in socioeconomic status (SES).

SES, understood as an indicator of social class position using measurements of income, occupation, and education, has long been established as having a significant effect on health (Kitagawa and Hauser, 1973). SES is positively associated with health, where people with high levels of SES generally live longer and healthier lives than people with low levels of SES who suffer from more illnesses and die younger (Dastra et al., 2005; Huisman et al., 2005; Marmot et al., 1997; Minkler et al., 2006). Because SES has also been shown to vary significantly across racial groups, with blacks experiencing lower SES than whites, researchers have often focused on racial SES differences as generating the black/white health disparity. However, while it is necessary to take SES into account when attempting to understand racial health disparities, it cannot be understood as the sole force patterning such disparities. For example, some research has 
demonstrated the persistence of disparities after having controlled for the effect of SES on health (Farmer and Ferraro, 2005).

Furthermore, forces of racism and racial discrimination, both past and present, continue to shape the lives and life-chances of blacks living in the United States. As such,

SES is not just a confounder of racial differences in health but part of the causal pathway by which race affects health. Race is an antecedent and determinant of SES, and racial differences in SES reflect, in part, the successful implementation of discriminatory policies premised on the inferiority of certain racial groups (Williams, 1999).

Racial categorization continues to have a powerful role in determining not only SES but other structural inequalities such as segregation which can greatly affect health as well. Therefore, racial health disparities should be understood as patterned both by racial differences in SES as well as simply a consequence of racism in general. In other words, race and SES shape racial health disparities separately as well as conditionally and this complex relationship remains largely unexplained. Further research regarding the role of SES in racial health disparities is needed. This research attempts to add to the body of literature by examining race differences in the effect of education on health over the lifecourse. 


\section{LITERATURE REVIEW}

\section{Health Inequality}

Research regarding health has demonstrated clear social patterning in the distribution of illness. While some of the patterns in the distribution of illness that exist between different population groups reflect biological attributes, such as the different levels of health experienced by the young and the elderly, other differences in health between groups reflect social inequities. Marginalized and disadvantaged populations have persistently experienced a disproportionate burden of mortality and morbidity. For example, there is a clear association between low SES and poor health, which can be seen in a number of indicators including lower life expectancy and higher overall mortality rates. (Buck, 1981; Dutton, 1986; Illsley and Mullen, 1985; Adler et al., 1994; Pappas et al., 1993)

The World Health Organization (WHO) makes a distinction between health inequality and health inequity. While the WHO defines health inequality as any "differences in health status or in the distribution of health determinants between different population groups" the definition goes on to clarify that health inequity should be understood as the unfair and uneven distribution of health conditions attributable to external environments or conditions that are primarily out of the control of the individual. (WHO, 2011) In other words, health inequity, according to the WHO, should be understood as unavoidable differences in health that unevenly affect some population groups. However, the concepts of "unavoidable conditions" or "outside of the control of the individual" which the WHO uses to establish the presence of inequity are vague and 
may not take into consideration the idea that social conditions can shape individually based risk factors that lead to disease.

In their work, "Fundamental Causes of Disease," Bruce Link and Jo Phelan argue that health researchers need to contextualize individually based factors that contribute to differences in health between population groups, such as diet and exercise. The authors write, "For example, there are powerful social, cultural, and economic factors shaping the diet of poor people in the United States" (Link, 1995:85). In other words, unhealthy behavior that could be understood as avoidable and within the control of the individual, such as smoking or poor diet, should be understood as context-dependent in the sense that there are significant social forces which influence behavior and as a result, health outcomes (Link, 1995). As such, for the purpose of this research, a definition of health inequality that takes into consideration the social forces that shape behavior is necessary.

The working definition of health inequality employed in this research is that of Paula Braveman. In her essay, "Health Disparities and Health Equity: Concepts and Measurement" Paula Bravemen defines health inequality as the following:

A health disparity/inequality is a particular type of difference in health or in the most important influences on health that could potentially be shaped by policies; it is a difference in which disadvantaged social groups (such as the poor, racial/ethnic minorities, women, or other groups that have persistently experienced social disadvantage or discrimination) systematically experience worse health or greater health risks than more advantaged groups (Braveman, 2006:180).

This definition of health inequality is useful because it includes a consideration of not just differences in health but also differences in the "most important influences on health". This consideration essentially incorporates the powerful social forces at work in 
determining a person or group's level of health. In terms of this research, Braveman's definition of health inequality is fitting in that it allows for the possibility that a health inequality, such as the disparity seen in health outcomes of white and black Americans, can arguably be understood in terms of the effect that a social system, such as education, has in determining health because there are significant structural determinants of education such as racial segregation.

In terms of the effect of education on health, the primary structural determinants which result in racial disparities are the unequal opportunities for education and especially quality education experienced by blacks and whites.

\section{Racial Health Inequalities}

African Americans make up a disadvantaged social group that has persistently experienced worse health than whites and other racial/ethnic minority populations. For example, according to the National Center for Health Statistics (NCHS) report regarding health in the United States in 2009, blacks were shown to have the highest mortality rate of any racial/ethnic group with an age adjusted death rate of 1,006.2 per 100,000 between the years 2004-2006 (NCHS, 2010). During the same time period the rate was 777.8 per 100,000 for whites and 579.5 per 100,000 for Hispanic/Latinos (NCHS, 2010). In terms of infant mortality rates as an indicator of population health, according to the Commonwealth Fund publication, "Racial and Ethnic Disparities in U.S. Health Care," African-Americans had the worst rates of all the racial groups measured, with a rate 2.5 times greater than that for whites in 2003 (Mead, 2008). Blacks are also more likely to rate their overall health as either fair or poor (Ferraro et al., 1997; Hughes and Thomas, 
1998; Mutchler and Burr, 1991) as well as to report having a chronic illness or functional disability (Clark and Maddox, 1992; Fried et al., 2003; Kelly et al., 2004; Mead, 2008 Ostchega et al., 2000; Schoenbaum \& Waidmann, 1997).

Additionally, according to a 2009 report regarding health inequalities published by the American Society of Clinical Oncology (ASCO) based on data from the National Cancer Institute (NCI), African Americans have higher incidence and death rates from cancer than any other racial group (ASCO, 2009). In fact, as of the 2008 American Cancer Society (ACS) publication of "Cancer Facts \& Figures," African American males experienced a cancer-specific death rate that was about 37 percent higher than that of white males and for African American females it was about 17 percent higher than white females (ACS, 2008). Blacks also experience the highest rate of HIV infection in the United States, with a case rate 10 times that of whites (Mead, 2008).

The black/white health disparity is one of the most robust and persistent racial inequality in health and as such, has received a great deal of attention by social and medical researchers. However, although scholars and researchers interested in racial health inequalities frequently rely on racial categorization, it is generally agreed that race is a socially constructed concept with no biological basis (LaVeist, 2005b).

According to Thomas LaVeist's conceptual model of race, known as the physiognomy model, in the United States individuals both self-identify and are socially categorized as specific races in terms of the manifest indicator of skin color as well as parental racial categorization. Individuals are then exposed to different environmental and socially deterrmined health risks depending on the way they have been racially 
categorized (LaVeist, 1994). The experience of being a member of one racial group or another can vary substantially in terms of discrimination and social privilege. Although race, as a concept, has no biological basis it is used to categorize people and such racial categorization produces inequality. Thus disparities in the health of black and white Americans have been established as socially patterned as opposed to being rooted in individual characteristics. This is to say that the health disparity between black and white population groups is a result of social consequences of racial categorization rather than any genetic differences between the two groups (Lillie-Blanton, 1996).

Furthermore, although race is a socially constructed concept, it has resulted in very real consequences, some of which have drastically affected health outcomes. This sentiment is echoed in the work of David R. Williams and Pamela Braboy-Jackson who write, "Race is a marker for differential exposure to multiple disease-producing social factors. Thus racial disparities in health should be understood not only in terms of individual characteristics but also in light of patterned racial inequalities in exposure to societal risks and resources" (Williams and Braboy-Jackson, 2005:325). In their article "Social Sources of Racial Disparities in Health" Williams and Braboy-Jackson examine black/white health disparities in the U.S. by comparing five causes of death (homicide, heart disease, cancer, pneumonia and flu, and suicide), noting that racial disparities in mortality exist for some causes (homicide, heart disease, and cancer) and not for others (pneumonia and flu, and suicide) (Williams, 2005). In their examination of racial disparities in health in terms of the patterned nature of mortality rates, the authors identify possibly responsible social sources such as racial differences in socioeconomic 
status, neighborhood residential conditions and medical care (Williams, 2005). In other words, the authors argue that the health risk factors people are exposed to are determined by social forces such as, differences in SES, neighborhood residential conditions and medical care.

\section{Socioeconomic Explanations}

In attempts to understand the black/white health disparity, some researchers have focused on the socioeconomic gradient in health. In terms of the social patterning of health, the principle measures of SES, income, occupational prestige and level of education, are possible mechanisms at work in the racially unequal distribution of health. Previously, researchers have hypothesized that the differences in health status among black and white populations in the United States are due to racial differences in SES (Jackson, 1985; Markides and Mindel, 1987). Some research has demonstrated that controlling for SES results in the disappearance of racial health differences. For example, findings of Fuller-Thomas et al. suggest that the disparity in disability experienced by black and white Americans is primarily due to the disproportionate number of African Americans with lower levels of SES (Fuller-Thomas, 2009).

However, while SES is highly correlated with race, both predict health status independently (LaVeist,2005a). Even when comparing white and black Americans that have experienced similar SES or environmental conditions, blacks bear the burden of the added negative effect of belonging to a population group that experiences racism and discrimination (Williams, 1999). 
In fact, some studies have demonstrated the persistence of a disparity despite controlling for SES. For example, Farmer and Ferraro analyze data from the Nutrition Examination Survey I (NHANES): Epidemiologic Follow-up Study (NHEFS) in order to address the research questions, "does the SES/health relationship differ for white and black Americans? And might the SES/health relationship be dependent on the health measure considered?" (Farmer, 2004;193). The researchers found that although increases in SES correlated to increases in self-rated health for whites, it did not correspond to health gains for blacks which resulted in a large racial gap in health status among those within the highest level of SES (Farmer, 2004). Another example of why health disparities cannot simply be explained by socioeconomic status can be seen in infant mortality rates, where rates for highly educated black women remain higher than for less educated white women (Pamuk et al., 1998). This research clearly demonstrates that SES can affect health differently for members of different racial groups.

The relationship between race and SES should be understood as conditional, meaning that there is an interaction effect between race and class in predicting health outcomes (Collins, 2000; LaVeist, 2005a; Pappas, 1994; Pettigrew, 1981; Wilson, 1980). Navarro writes "The issue is not race or class. The issue is race and class" (Navarro, 1991:341). In other words, research aimed at understanding racial health disparities should focus on the way race and SES affect health separately as well as conditionally rather than attempt to explain disparities in terms of either race or SES. Additionally, while there has been some debate around the direction of causality in terms of the link between SES and health, a number of cohort studies suggest the direction of influence is 
indeed low SES leading to poor health as opposed to poor health causing downward social mobility (Doornbos and Kromhout, 1990; Fox et al., 1985; Power et al., 1990; Wilkinson 1986).

\section{The Effect of Education on Health}

Although SES is typically understood and operationalized as the combined influence of income, education, and occupation, many studies show that in fact education alone is a significant predictor of health across a variety of outcomes (Antonovsky, 1967; Crimmins and Saito, 2001; Elo and Preston, 1996; Goesling, 2007; House et al., 1994; Kitagawa and Hauser, 1973; Mirowsky and Ross, 2003; Rogers, Hummer and Nam, 2000; Ross and Wu, 1995,1996; Schnittker, 2004; Vargas, Ingram and Gillum, 2000). Individuals with higher levels of education are less likely to report morbidity in terms of most common acute and chronic diseases (Cutler and Lleras-Muney, 2006).

Additionally, education has been shown to be more closely associated with health behaviors such as exercise and smoking than income or occupation (Winkleby, 1992).

As such, education has increasingly developed as the primary marker of SES in mortality and health studies with many researchers arguing that it is a better measure than income or occupation. There are a couple of important factors which make education an advantageous instrument for measuring SES. For example, education is a measure which can be obtained for everyone as opposed to income or occupation which cannot always be determined in a way that accurately measures SES. This is especially true for stay-athome parents and retired individuals (Elo and Preston, 1996). 
Education is also understood as an advantageous measure of SES because for the vast majority of individuals it remains constant over the life-course once they have reached early adulthood. This is useful because it means that level of education will not be altered by a health impairment that happens in adulthood. In contrast, income and occupation are likely to change a number of times over the life-course of any given individual and can be significantly affected by injuries or health impairments. Furthermore, the unvarying nature of education is also beneficial to researchers measuring the effect of SES on health because at any given moment when data are being collected an individual's level of education can be used to accurately predict their future and past levels of education. This is not the case with income or occupation where a certain level of income or occupation status is not indicative of future or past levels or statuses (Elo and Preston, 1996; Freedman and Martin, 1999).

As education has become more frequently used as the primary measure of SES, researchers have had to ask the question, how does education affect health? A number of theoretical explanations for the relationship between education and health have been developed. These theoretical explanations describe possible mechanisms at work in linking education to health. The mechanisms described fall into four main categories (1) work and economic conditions, (2) social-psychological resources, (3) information and cognitive skills, and (4) health behavior (Cutler and Lleras-Muney, 2006; Elo and Preston, 1996; Ross and Wu, 1995).

First, education affects health because level of education structures both employment and income. "Hundreds of studies in many different countries and time 
periods have confirmed that better-educated individuals earn higher wages, experience less unemployment, and work in more prestigious occupations than their less-educated counterparts" (Card, 1999). Income and employment directly affect an individual's ability to access material resources such as food, housing, and health care services, which are critical in terms of a person's health (Elo and Preston, 1996). However, there is evidence that the effect of education on health does not simply occur through the mechanisms of employment and income. For example, the completion of a degree is associated with income benefits such as higher earning capacity. If work conditions were the only mechanism structuring the effect education has on health, there would likely be an association between the completion of a degree and an increase in health. However, there is evidence showing that there is no additional health benefit associated with the completion of a degree (Cutler and Lleras-Muney, 2006).

Second, education affects health as it shapes social-psychological resources, in particular, sense of control and social support. In terms of sense of control, education increases a person's ability to problem solve and communicate which can increase their sense of control within their own lives and any challenging situations that they may face. Ross and $\mathrm{Wu}$ argue that this is a valuable social-psychological resource for health as sense of control can enhance health related behavior, and because lack of personal control is associated with suppression of the immune system (Rodin and Timko, 1992; Rowe and Kahn, 1987). Social support is the other primary social-psychological resource understood to link education and health. People with higher levels of education are more likely to have higher levels of social support (Eckenrode, 1983; Ross and Mirowsky, 
1989) which improves health by decreasing psychological problems like depression and anxiety (Kessler and McLeod, 1985; LaRocco, House, and French, 1980) and by possibly increasing likelihood of practicing protective health behaviors.

Cutler and Lleras-Muney suggest that education may affect health through an increased sense of value for the future. Because higher levels of education provide an individual with increased opportunities for income and occupational rank or prestige, it might also improve one's general attitude. An improved attitude and outlook on the future may then increase an individual's likelihood of investing in and protecting their future. One way they might be inclined to do so is through health promoting activities and behavior.

The third main mechanism believed to link education to health is that of information and cognitive skills (Cutler and Lleras-Muney, 2006; Elo and Preston, 1996). This theory poses that people with higher levels of education have better access to information and improved critical thinking skills. In terms of health, access to information about healthy behavior and health promoting technologies or medicines as well as the ability to understand and put that information to use, is paramount. "Education might matter for health not just because of the specific knowledge one obtains in school, but rather because education improves general skills, including critical thinking skills and decision-making abilities" (Cutler and Lleras-Muney, 2006:15). For example, this relationship can be seen within people who have HIV/AIDS or diabetes, where those with higher levels of education are shown to be more likely to follow the treatment regimens accurately (Cutler and Lleras-Muney, 2006). 
The last category of mechanisms at work in linking education and health is that of health lifestyle. Ross and $\mathrm{Wu}$ focus on four mechanisms within this category which are smoking, exercise, drinking, and health check-ups. Education increases the likelihood that an individual will take part in healthy activities such as exercise (Ford et al., 1991; Helmert et al., 1989; Jacobsen and Thelle, 1988; Leigh, 1983; Shea et al., 1991) and doctor visits (Coburn and Pope, 1974) as well as the likelihood that they will abstain from unhealthy activities such as smoking (Helmert et al., 1989; Jacobsen and Thelle, 1988; Liu et al., 1982; Matthews et al., 1989; Miler and Wigle, 1986; Shea et al., 1991; Wagenknecht et al., 1990; Winkleby et al., 1992)) and excessive drinking (Darrow et al., 1992; Midanik et al., 1990; Romelsjo and Diderichsen, 1989).

Research which aims to further understanding regarding racial health disparities as they relate to SES should consider the relationship between education and health. Education has been shown to have a significant positive effect on health and the relationship is believed to operate through mechanisms of work and economic conditions, social-psychological resources, information and cognitive skills, and health behavior. These mechanisms should be understood as playing an important role in the effect education has on racial health disparities. As such, an examination of the effect of education on health should focus on the way in which these mechanisms operate to promote health over the life-course. 


\section{Health Disparities and the Life-Course}

The relationship between the education-health gradient and racial health disparities is further complicated by possible variation over the life-course. Economic factors, social-psychological/interpersonal resources and health behaviors, all believed to mediate the relationship between education and health, have properties that could produce variation in the relationship over the life-course (Lynch, 2003). Also, the relationship between SES and racial health disparities in predicting health is complex and becomes more so when one considers the effect of age on the relationship. Furthermore, in-depth understanding of any health related relationship requires consideration of the life-course. Some previous literature has addressed the way in which health disparities vary over the life-course and has produced hypotheses regarding how the relationships will vary and why. The cumulative advantage hypothesis and the double jeopardy hypothesis predict that health disparities will grow over the life-course; the age-as-leveler hypothesis predicts that health disparities will diminish over the life course and the mortality as leveler hypothesis predicts a non-linear life-course pattern in health disparities.

Double-Jeopardy Hypothesis: Racial Health Disparities Grow

The double jeopardy hypothesis predicts that racial health disparities will increase over the life course. The hypothesis explains that the negative effects of belonging to a racial minority are increased over the life-course with the negative effects of aging on health (Ferraro and Farmer, 1996). As such, the health of blacks decreases at a faster rate 
than the health of whites and the racial health disparity grows, becoming largest in older ages.

\section{Cumulative Advantage Hypothesis: Education-Health Disparities Grow}

The cumulative advantage hypothesis states that the positive effect of having high levels of education will grow over the life-course resulting in the largest gap in health between the two groups appearing in older ages. Robert K. Merton was the first to propose the idea of cumulative advantage and he wrote about it with regards to scientific research. He claimed that in systems of stratification, those with the highest rank enjoy privileges that essentially give them an advantage and in turn increase their rank. As a byproduct, those with the lowest rank become relatively ranked even lower. Merton gives the following example; "the principle of cumulative advantage ... operates in many systems of social stratification to produce the same result: the rich get richer at a rate that makes the poor become relatively poorer" (Merton, 1968:62).

In terms of the effect of education on health, researchers have used the cumulative advantage hypothesis to predict the way that the relationship will operate over the lifecourse. This is to say that the disparity in health outcomes grows with age because the resources that link higher levels of education with better overall health accumulate through life (Ross and $\mathrm{Wu}, 1996)$. Some previous research has found support of the cumulative advantage hypothesis (Lauderdale 2001; Lynch 2003; Meara 2008; Ross 1996). Wealth, which can be understood as a useful resource and is often structured by education, has a significant effect on health, and accumulates over the life-course. Individuals with higher levels of income not only make more money but can save more 
money. Savings can make money through interest as well as provide a buffer which helps avoid borrowing money at high interest rates. As such the education structured resource of income can accumulate over the life-course. Similarly, the socialpsychological resources, healthy behaviors and habits as well as cognitive thinking and problems solving skills which are structured by education can accumulate over the lifecourse and could result in a large gap in health outcomes between the highly educated and poorly educated. The cumulative advantage hypothesis predicts that this is the pattern by which education affects health over the life-course.

Age-as-Leveler Hypothesis: Racial Health Disparities Diminish

The age-as-leveler model has also been applied to racial health disparities, and the way in which they operate over the life-course. In terms of racial health disparities the age-as-leveler hypothesis states that the health disparity between blacks and whites will be smallest among those in old age. According to Ferraro and Farmer, racial health disparities between African-Americans and whites will diminish over the life-course because African Americans develop coping strategies to deal with discrimination and are therefore more capable of dealing with age discrimination. As a result, blacks are actually better off in older ages relative to younger ages which produces an increase in their health while whites experience solely the decrease related to age. As a result, the health disparity is believed to decrease over the life-course (Ferraro and Farmer, 1996). Age-as-Leveler Hypothesis: Education-Health Disparities Diminish

In terms of the relationship between education and health, the age-as leveler hypothesis predicts that educational differences in health diminish over the life course 
and that as a result the gap in health between the two groups is reduced in older ages. The theoretical explanations for this life-course pattern have to do with proximity and social policy. First, proximity is understood as shaping the convergence of health outcomes over the life-course in that younger people are more likely to either be currently attaining education or to have more recently completed their schooling. As such, the positive effects of education on health will be stronger at that time in the life-cycle. Second, social policy is understood as structuring the life-course pattern in the educationhealth relationship in that older populations receive health promoting social services which in turn levels the health disparity. For example, social security and Medicare are programs which potentially work to even out the health of the poorly educated and the highly educated. Also, the age-as-leveler hypothesis states that over the life-course the effect of age on health is so powerful that health outcomes are primarily tied to age and effects of education on health become less important. Previous research has found support of the age-as leveler hypothesis (Becket, 2000; House, Kessler and Herzog, 1990).

\section{Mortality-as-Leveler: Education and Racial Health Disparities Grow and Diminish}

The mortality-as-leveler hypothesis, which can be applied to both racial and education-health disparities, is essentially a combination of the cumulative advantage hypothesis and the age-as-leveler hypothesis which conceptualizes selective mortality as the uniting factor. Both, the cumulative advantage hypothesis and the age-as-leveler hypothesis have been criticized as not taking into account the effect of premature death on health disparities especially for later life stages. Selective mortality is understood as 
the earlier death of the least healthy which results in unequal comparisons of health between groups. With regards to education-health disparities selective mortality would be understood as the phenomenon where the low level of health in the least educated eventually results in their death which happens before the healthy uneducated as well as both the healthy and unhealthy highly educated. As a result, comparisons between the highly educated and the poorly educated, after the age range where the selective mortality happens, show a leveling in health outcomes between the two groups because only the healthiest of the least educated are being compared to both the healthy and unhealthy of the highly educated. Or

\begin{abstract}
If the cumulative-advantage hypothesis is true, then at some point low levels of education lead to mortality, and the surviving population will consist of robust persons with low levels of education and highly educated persons. Ultimately, variance in education is reduced, weakening the effect of education. More important, this reduction of the subpopulation with low levels of education to the most robust causes the mean for health indicators to appear to increase or, at least, causes its decline across age to slow, making the health of subpopulations with low and high levels of education appear to converge (Lynch, 2003: 315).
\end{abstract}

In other words, while the cumulative advantage hypothesis may be accurate in stating that the effect of education on health grows over the life-course, the age-as-leveler hypothesis may also be accurate in predicting that health disparities do diminish over the life-course. The mortality-as-leveler hypothesis states that education-health disparities will grow in the beginning of the life-course until middle age when selective mortality will occur and then the disparity will diminish at the end of the life-course as the least healthy members of the least educated group die at disproportionate rates.

In terms of racial health disparities, selective mortality operates the same way only it is the least healthy blacks who die earlier and the later in life comparison is 
between the healthiest blacks and both the most healthy and least healthy whites. The mortality-as-leveler hypothesis can also be understood in terms of racial health disparities. In this case the hypothesis would predict that the health disparity between blacks and whites will grow in the beginning of the life-course until middle age when selective mortality will occur and then the disparity will diminish at the end of the lifecourse as the least healthy blacks will die at disproportionate rates. While there are hypotheses regarding life-course patterns for racial health disparities and for educationhealth disparities there is limited research regarding racial differences in the life-course pattern of the effect of education on health.

\section{Research Questions and Hypotheses}

RQ1: Do whites experience higher education returns on their overall health than blacks? If the health benefits of education are different for blacks than for whites, there is clear evidence that racial health disparities are patterned by the synergistic effect of race and SES together.

H1: I hypothesize that the effects of education on health will be stronger for whites than for blacks.

$R Q 2: \quad H o w$ do educational differences in health change with age?

This question addresses whether or not the education-health disparity grows or diminishes over the life-course. If the mortality-as-leveler hypothesis is correct, the effect of education will grow with age resulting in a widening in educational differences in health, until late-middle ages where selective mortality of the least educated/least 
healthy will result in the leveling of health between the least educated and the highly educated. This will produce a diminished education-health disparity.

H2: I hypothesize that education level differences in health status will grow in the beginning and middle of the life-course and then diminish at the end of the life-course in accordance with the mortality-as-leveler hypothesis.

$R Q 3:$ How does the patterning of the effect of education on health over the life-course vary between blacks and whites?

This question is aimed at discovering whether or not there are racial differences in the effect of education on health over the life-course. If the first hypothesis of this research is supported and blacks are shown to receive smaller health returns on education than whites, then race disparities in health will be greater for the highly educated than for the poorly educated. Also, if the second hypothesis of this research is supported and education related differences in health grow and then diminish as a result of selective mortality, then the combined selective mortality of the least healthy blacks as well as the least healthy poorly educated will result in a more drastically diminished educationhealth disparity for blacks than for whites.

H3: I hypothesize that the racial difference in health returns on education will result in a growing disparity between blacks and whites over the life-course. 


\section{METHODS}

\section{Data}

This research uses data from the 1982-2009 United States National Health Interview Survey (NHIS). The NHIS collects information on a variety of health and sociodemographic topics and is widely used in health related research. The NHIS is a cross-sectional household interview survey with a multistage area probability design that permits the representative sampling of households and non-institutional group quarters within the U.S. Sampling and interviewing are continuous throughout each year and the survey has been conducted every year since 1957. The Integrated Health Interview Series (IHIS) provides integrated data and documentation of the NHIS since the 1960's.

Data from 28 survey years, 1982-2009, were pooled to allow for analysis of individual life-course trajectories in terms of health outcomes. The survey years 19822009 were chosen for analysis because the survey question used to measure level of education was a consistent continuous measurement over these years. Prior to 1982 the education variable was measured using fewer response categories and as such did not capture the same variations in level of education. Also, pooling this many years of data allows for analysis in terms of synthesized cohorts.

The initial sample size was $\mathrm{N}=2,783,810$. As the focus of this research is the persistent and significant black/white health disparity, the race variable includes only those respondents who report being black or white. Additionally, respondents who report Hispanic ethnicity were excluded in order to focus on non-Hispanic blacks and nonHispanic whites $(\mathrm{N}=2,215,257)$. The analytic sample is composed of respondents 
between ages 25 and 84 with the assumption that those respondents over the age of 25 are more likely to have completed their education and because the NHIS top coded 85 to include respondents ages 85 and older. $(\mathrm{N}=1,415,268)$ Additionally, cases with missing values for the self-rated health (6067 cases with missing values, $\sim 0.4 \%$ ) and education (24906 cases with missing values, $\sim 1.8 \%$ ) variables were also excluded producing a final sample size of $\mathrm{N}=1,386422$. The frequencies, percentages, range, and mean or standard deviation for all of the variables used in this research are reported in Table 1.

[Table 1 here]

\section{Measures}

\section{Dependent Variable}

\section{HEALTH STATUS}

The health variable which measures self-rated health was used as the dependent variable in this research. Self-rated health status is obtained with a question asking respondents to rate their overall health as "excellent", "very good", "good", "fair", or "poor". Self-rated health has been shown in previous studies to be a good measure of health across racial and ethnic groups (Chandola and Jenkinson, 2000). The health variable was recoded into a dichotomous variable with excellent, very good, and good health coded as 1 indicating the presence of good health, and fair and poor health coded as 0 indicating an absence of good health. The variable was coded as a dichotomous variable so that the data could be analyzed with binary logistic regression. 


\section{Independent Variables}

$\underline{\text { RACE }}$

Race is the primary independent variable used in this analysis. The race variable was used with non-Hispanic whites as the reference category coded as 0 and nonHispanic blacks coded as 1.

\section{$\underline{\text { EDUCATION }}$}

Education is also an independent variable used in this research. The education variable measures respondents' highest year of education achieved with "never attended/kindergarten only" coded as 0 , first grade -twelfth grade coded as 1-12, "1 to 3 years of college" coded as 14, "4 years of college/Bachelor's degree" coded as 16 and "5+ years of college" coded as 18 .

\section{$\underline{\mathrm{AGE}}$}

Age is also used as an independent variable in order to analyze trends in the effect of education on health over the life-course. The age variable is continuous and was recorded as respondents' age in years since their most recent birthday. The age variable was centered on 25 (coded as 0-59) to simplify the interpretation of the coefficients for the interaction terms that include age and a categorical variable.

\section{Control Variables}

\section{$\underline{\text { BIRTH COHORT }}$}

Birth cohort was used to control for differences in health that may have resulted from year of birth. The birth cohort variable was computed by subtracting respondent age from survey year. Since the survey years range from 1982-2009 and the ages range 
from 25-84, the birth cohort variable ranges from 1898-1984 with the mean birth year of 1946. Birth cohort was centered on the year 1898 because this simplifies interpretation of the coefficients for interaction variables that include birth cohort.

$\underline{\text { SEX }}$

The sex variable was also used in order to control for any differences in health due to sex. Male was made the reference category coded as 0 and female was coded as 1 .

\section{GEOGRAPHIC REGION}

Geographic region was used as a control variable, with Northeast, North/Central Midwest, and West coded into three separate dichotomous variables and South used as the reference category.

\section{$\underline{\text { AGE X BIRTH COHORT }}$}

An interaction variable between age and birth cohort was created in order to control for the interaction effect of year of birth and age. This variable is used to control for the possible differences in the effect age has on health that are determined by when a person was born. In other words, this variable is used to control for the fact that life expectancy at birth increased between 1898 and 1984, which is the range of birth years for respondents included in this research.

\section{$\underline{\text { SQUARE TERM OF AGE }}$}

The square term of age was also included in order to allow for the non-linear relationship between age and health. 


\section{EXCLUDED MEASURES}

Finally, three variables were considered for analysis but were excluded. First, income was considered for analysis however was ultimately excluded from analysis as not theoretically necessary as well as problematic for a couple of reasons. Education has been shown to be a significant predictor of health and increasingly research is being conducted using education as the primary and single measure of SES (Antonovsky, 1967; Crimmins and Saito, 2001; Elo and Preston, 1996; Goesling, 2007; House et al., 1994; Kitagawa \& Hauser, 1973; Mirowsky and Ross, 2003; Rogers, Hummer and Nam, 2000; Ross and Wu, 1995,1996; Schnittker, 2004; Vargas, Ingram and Gillum, 2000). Income is also a problematic variable for a number of reasons. First, measurements of income tend to produce variables with a lot of missing values as respondents are often hesitant to report their income level. Also, this research is interested in examining health on the individual level and income is not usefully measured at the individual level. Measures of individual income do not take into account the additional amount of money contributed by other household members or the number of people being supported by the individual income. Family household measures of income do not take into account household size.

Additionally, employment status is very inconsistent and can change frequently

which can result in income levels being misleading. For example, although an individual may report a high level of income it is conceivable that their current income level is relatively new and that for the majority of their working life the individual was in fact living on much less. 
The use of survey year as a control variable was considered in order to account for any changes in self-rated health over time. However, the mean value for the dependent variable, health was not shown to vary across survey years and the variable was therefore not relevant for analysis. 


\section{Analytic Strategy}

Data analysis began with univariate analysis of the dependent variable to check for normal distribution, missing cases, and level of measurement. Next, descriptive analyses were used to determine frequencies and distribution within independent and control variables.

Bivariate analysis was used to examine the black/white health disparity in self-rated health.

There are three two-way interaction terms included in this analysis. Interaction terms are included because sometimes the effect of one independent variable is dependent on the level of another independent variable. For example, the first two-way interaction term used is between education and race. The education*race interaction term is used with the assumption that level of education might affect level of health differently for people of different races. For this reason the interaction term is used to measure the effect of education on health for blacks and whites separately.

Second, in order to compare the way age affects health for blacks and whites an interaction term between race and age was created. This term captures the probability of being healthy over the life-course separately for blacks and whites. Additionally, for the purpose of determining changes in the effect of education on health over the life course an interaction term between education and age was created. This term is used with the assumption that the effect of education on health may be partially dependent on age.

Finally, a three-way interaction term between race, education and age was created in order to analyze the life-course pattern of education differences in health across races. 
This term is included to address the second research question regarding the racial differences in the effect of educational on health over the life course.

For the purposes of logistic regression a weight was created and used to adjust for oversampling of racial minorities. Binary logistic regression was used to analyze the effect of education on health across racial and age groups. Model 1 estimates the effects of race, education and age on health and the results were interpreted using the following equation: Effect of Race on Odds of having good health $=\left(\operatorname{Exp}\left(\beta^{*}\right.\right.$ Race $\left.)\right)$. In Model 2 demographic control variables were added and the effects of race, education and age on health were measured. The results were interpreted using the following equations: Effect of Education on Odds of good health $=\left(\operatorname{Exp}\left(\beta^{*}\right.\right.$ Education $)$, Effect of Age on Odds of good health=1-(Exp $\left(\beta^{*}\right.$ Age $\left.)\right)$ and Effect of Race on Odds of good health $=(\operatorname{Exp}(\beta$ *Race)).

Model 3 includes the interaction term between race and education in order to address the first research question regarding racial differences in education returns on health. The results of model three were interpreted using the following equations, Effect of Education on the Odds of good Health $=\operatorname{Exp}((\beta 1+\beta 2 *$ Race $)$ Edu $))$ and Probability of Good Health $=\left(\operatorname{Exp}\left(\beta 0+(\beta 1 * R A C E)+(\beta 2 * E D U)+(\beta 3 * A G E)+\left(\beta 4 * A G E^{\wedge} 2\right)+\right.\right.$ $(\beta 5 * S E X)+(\beta 6 * C O H O R T)+(\beta 7 * A G E * C O H O R T)+(\beta 8 * N E)+(\beta 9 * N / C E N)+$ $(\beta 10 * W E S T)+(\beta 8 * R A C E * E D U))) /(1+(\operatorname{Exp}(\beta 0+(\beta 1 * R A C E)+(\beta 2 * E D U)+$ $(\beta 3 * A G E)+\left(\beta 4 * A G E^{\wedge} 2\right)+(\beta 5 * S E X)+(\beta 6 * C O H O R T)+\left(\beta 7 * A G E^{*} C O H O R T\right)+$ $(\beta 11 * N E)+(\beta 9 * N / C E N)+(\beta 10 * W E S T)+(\beta 11 * R A C E * E D U))))$. 
Model 4 includes the interaction term between age and race in order to investigate racial differences in health over the life-course. The results of model 4 were interpreted using the following equations, Effect of age on the Odds of good health $=\operatorname{Exp}((\beta 1+$ $\beta 2 *$ Race $)$ Age $)$ and Probability of Good Health $=(\operatorname{Exp}(\beta 0+(\beta 1 * R A C E)+(\beta 2 * E D U)+$ $(\beta 3 * A G E)+\left(\beta 4 * A G E^{\wedge} 2\right)+(\beta 5 * S E X)+\left(\beta 6^{*} C O H O R T\right)+\left(\beta 7 * A G E^{*} C O H O R T\right)+$ $\left.\left.(\beta 8 * N E)+(\beta 9 * N / C E N)+(\beta 10 * W E S T)+\left(\beta 8 * R A C E^{*} A G E\right)\right)\right) /(1+(\operatorname{Exp}(\beta 0+(\beta 1$ $* R A C E)+(\beta 2 * E D U)+(\beta 3 * A G E)+\left(\beta 4 * A G E^{\wedge} 2\right)+(\beta 5 * S E X)+\left(\beta 6^{*} C O H O R T\right)+$ $\left(\beta 7 * A G E^{*} C O H O R T\right)+(\beta 11 * N E)+(\beta 9 * N / C E N)+(\beta 10 * W E S T)+$ $(\beta 11 * R A C E * A G E))))$

Model 5 includes the interaction term between age and education in order to estimate the effect of education on health over the life-course. The results of model 5 were interpreted using the following equations, Effect of education on Odds of good health $=\operatorname{Exp}((\beta 1+\beta 2 A g e)$ Education $)$ and Effect of age on the Odds of good health $=\operatorname{Exp}((\beta 1+\beta 2 *$ Education $)$ Age $)$ and Probability of Good Health $=(\operatorname{Exp}(\beta 0+(\beta 1$ $* R A C E)+(\beta 2 * E D U)+(\beta 3 * A G E)+\left(\beta 4 * A G E^{\wedge} 2\right)+(\beta 5 * S E X)+\left(\beta 6^{*} C O H O R T\right)+$ $(\beta 7 * A G E * C O H O R T)+(\beta 8 * N E)+(\beta 9 * N / C E N)+(\beta 10 * W E S T)+$ $(\beta 8 * E D U C A T I O N * A G E))) /(1+(\operatorname{Exp}(\beta O+(\beta 1 * R A C E)+(\beta 2 * E D U)+(\beta 3 * A G E)+$ $\left(\beta 4 * A G E^{\wedge} 2\right)+(\beta 5 * S E X)+\left(\beta 6^{*} C O H O R T\right)+\left(\beta 7 * A G E^{*} C O H O R T\right)+(\beta 11 * N E)+$ $(\beta 9 * N / C E N)+(\beta 10 * W E S T)+(\beta 11 * E D U C A T I O N * A G E))))$.

Finally, in Model 6 the three-way interaction term between race, education, and age was included in order to answer the second research question regarding whether or 
not the gap in education differences on health widens or narrows with age and how this pattern differs according to race. 


\section{FINDINGS}

\section{Results}

The results of the univariate analysis of the dependent variable indicate that 86.1 percent, the vast majority of respondents were shown to rate their health positively with 30.9 percent of respondents reporting excellent health, 29.5 percent report that their overall health is very good, and 25.8 percent of respondents report having good overall health. In contrast, only 13.8 percent rate their health negatively with 9.9 percent of respondents reporting fair health and 3.9 percent of respondents reporting poor health. In general, it appears that people assess their overall condition of health positively. Figures 1a and $1 \mathrm{~b}$ chart the dependent variable self-rated health.

[Figure $1 \mathrm{a}$ and $1 \mathrm{~b}$ here]

As shown in Figure 2, this research finds evidence of the black/white health disparity in terms of the indicator, self-rated health. While only 12.5 percent of whites rated their health as fair or poor, 22.1 percent of blacks reported negative health status.

[Figure 2 here]

Figure 3 charts racial differences in level of education and shows that levels do vary by race. Overall, whites were shown to be more likely to attain higher levels of education whereas blacks were shown to be more likely to receive lower levels of education. In fact, while only 15.7 percent of whites were shown to have less than a high school degree, 26.8 percent of blacks had not completed high school. Similarly, the racial pattern in level of education was reinforced at the higher levels of education with only 
13.7 percent of blacks reporting having more than a college degree and 24.9 percent of whites indicating that they had higher than a college degree.

[Figure 3 here]

Results of the bivariate analysis examining racial differences in level of health by level of education are charted in Figure 4 and demonstrate the positive association between education and health for both black and white populations. However, while higher levels of education were associated with better health for both population groups, whites were shown to have better self-rated health than blacks at every level of education.

[Figure 4 here]

The findings of this research also indicate racial differences in level of education by age as shown in Figure 5. Level of educational attainment declined with age beginning at around 50 years old for both blacks and whites. In other words, younger generations are attaining higher levels of education than older generations attained. While blacks were shown to have lower levels of education across generations, there was also a much steeper gradient in the level of education attained by older blacks. This is to say that in terms of the racial differences in levels of educational attainment, the gap in education between blacks and whites was shown to be largest in the oldest members of the populations. This racial gap in educational attainment seen between older blacks and whites is likely to affect the racial health disparity experienced by the two population groups. However, in terms of this research, the difference in educational attainment between blacks and whites due to age was controlled for using the birth cohort variable which measured the year of respondent birth. 
[Figure 5 here]

The unstandardized coefficients, odds ratios, standard errors, significance levels and the $-2 \log$ likelihood for logistic regression models 1-6 are shown in Table 2 and described below.

[Table 2 here]

According to the results of Model 1 which measures the effect of race, education and age on health separately, blacks are shown to be 47.3 percent lower odds than whites to report having good health. Additionally, for every year increase in education is associated with a 21 percent increase in odds of having good health and every year increase in age is associated with 3.6 percent decrease in the odds of having good health.

Model 2 also measures the effect of race, education and age on health separately, however, control variables for sex, birth cohort, age*cohort, and geographic region, were added in order to account for differences due to these demographic characteristics. According to the results of Model 2, having controlled for demographic differences, blacks still have 44.2 percent lower odds than their white counterparts to report having good health. The decrease in the coefficient for race from Model 1 to Model 2 indicates that the control variables help to explain some of the racial differences in the probability of having good health. Every year increase in education is still shown to be associated with a 21.6 percent increase in odds of having good health for both blacks and whites. Lastly, having controlled for demographic differences, every year increase in age is associated with 7.4 percent decrease in the odds of having good health. The increase in 
the coefficient for age from Model 1 to Model 2 may indicate that the control variables added to the model act as suppressors of the effect that age has on health.

According to the results of Model 3 a one year increase in education is associated with a 16.4 percent increase in the odds of reporting good health for blacks. In contrast, for whites, a one year increase in education is associated with a 22.9 percent increase in the odds of having good health. These results indicate that the positive effect of education on health is stronger for whites than for blacks. In other words, whites are shown to receive higher education returns on their health than their black counterparts. Figure 6 charts the interaction effect of education and race on health for mean values of age and birth cohort as well as the sex and geographic region reference categories of male and south respectfully.

\section{[Figure 6 here]}

Model 4 measures the interaction effect of race and age on health. According to the results of Model 4, and as shown in Figure 7, a one year increase in age for blacks is associated with a 6.9 percent decrease in the odds of being healthy.

[Figure 7 here]

For whites however, a one year increase in age is associated with a 7.5 percent decrease in the odds of being healthy. These results suggest that the negative effect of age on health is actually stronger for whites than for blacks. However, these findings could be a result of selective mortality where comparison at the oldest ages are between whites of all levels of health and only the blacks with the most robust health (Lynch, 2003). 
Model 5 measures the interaction effect of education and age on health.

According to the results of Model 5, in general before accounting for racial differences, every one year increase in education is associated with a 9.0 percent decrease in the negative effect of age on the odds of reporting good health. Here higher levels of education are shown to act as a buffer to the negative effects that age has on health. Additionally, according to the results of Model 5, every one year increase in age, once again before accounting for racial differences, is associated with a 26.6 percent increase in the positive effect of education on the odds of reporting good health. These results suggest that the positive effect of education on health grows over the life-course for both blacks and whites which is in accordance with the mortality-as-leveler hypothesis.

These results further support the mortality-as-leveler hypothesis as the educationhealth disparity is shown to grow and diminish over the life-course. Figure 8 a charts the education-health disparity, comparing whites with an $8^{\text {th }}$ grade education to whites with more than a college degree over the life-course.

[Figure 8a here]

According to these results, for those whites who have more than a college degree, the probability of having good health is extremely high and only declines slightly over the life-course. However, according to Model 5, for those whites who have only an $8^{\text {th }}$ grade level education, not only is the probability of having good health much lower to begin with, it rapidly declines over the life course until around age 60 where it levels out and eventually increases. 
Similarly, as shown in Figure 8b, the education health disparity grows and then diminishes over the life course for blacks as well.

[Figure 8b here]

However, the disparity in health between the highly educated blacks and poorly educated blacks is greater than between white groups. This is the case at every age and is especially true in the beginning and end of the life-course when the education-health disparity between blacks is almost double that of whites.

According to the results of Model 5 and as shown in Figure 9a,

[Figure 9a here]

although the life-course pattern in the education-health disparity is similar between blacks and whites, a racial health disparity persists. Blacks are shown to have lower probability of having good health at every age. Furthermore, this racial difference is even more pronounced in the highly educated. According to the results of Model 5 and as shown if Figure 9b,

[Figure 9b here]

although both blacks and whites with high levels of education have higher probabilities of having good health, the health of highly educated blacks appear to decline more rapidly over the life-course than for the highly educated whites. Also, among those with more than a college education, the racial health disparity grows over the life-course with the greatest disparity appearing in later life stages.

In Model 6 the three way interaction term between race, education and age was added in order to analyze the racial differences in the effect of education on health over 
the life-course. The coefficient for the three-way interaction term was not significant which suggests that there is no significant racial difference in the effect that education has on health over the life-course. In other words the life-course pattern in the effect of education on health is not significantly different across races. 


\section{Tables and Figures}

Figure 1a. Dependent Variable: Health

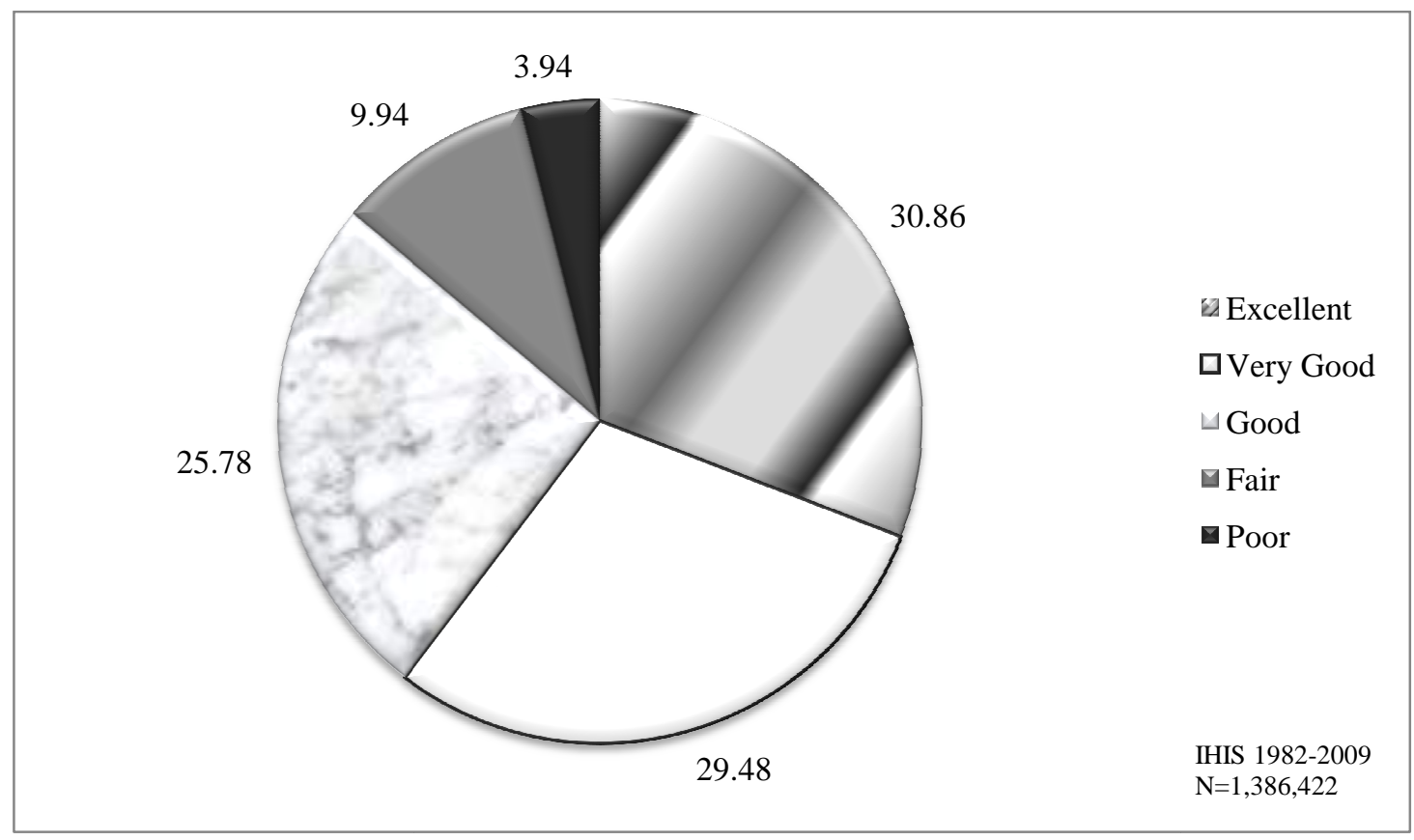

Figure 1b. Dependent Variable: Health recoded as dichotomous variable

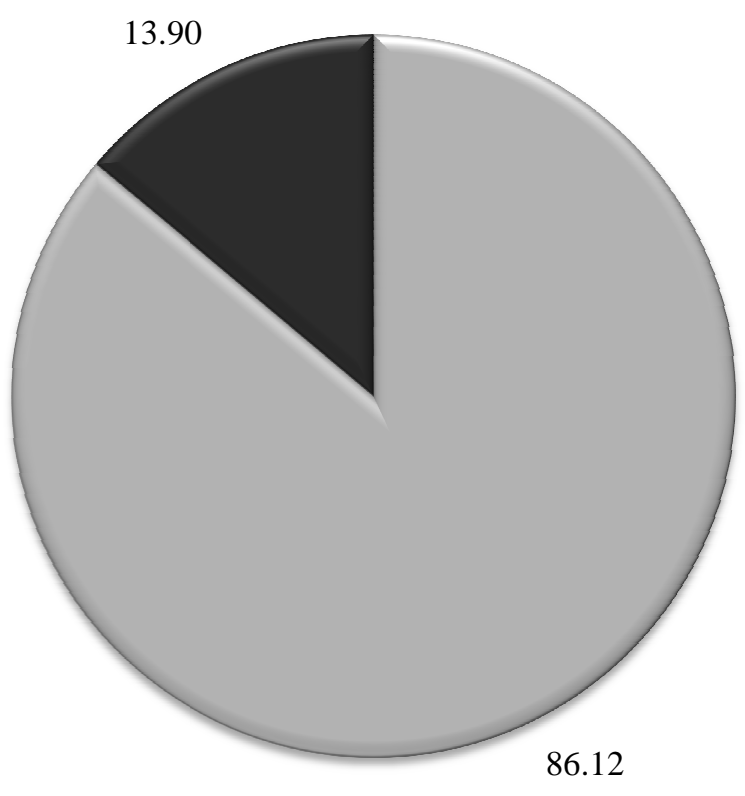

$\square$ Good Health

a Poor Health

IHIS 1982-2009

$\mathrm{N}=1,386,422$ 
Table 1. Descriptive Statistics

\begin{tabular}{|c|c|c|c|c|c|}
\hline \multicolumn{3}{|r|}{$\begin{array}{c}\text { Mean } \\
\text { (St. Dev.) }\end{array}$} & $\begin{array}{l}\text { Percentage } \\
\text { (Weighted) }\end{array}$ & $\begin{array}{c}\text { Frequencies } \\
\text { (Unweighted) } \\
\mathbf{N}=\mathbf{1 , 3 8 6 , 4 2 2}\end{array}$ & Range \\
\hline \multicolumn{6}{|l|}{ DV } \\
\hline & Good Health & & 86.7 & $1,194,001$ & \\
\hline & Poor Health & & 13.3 & 192,421 & \\
\hline \multicolumn{6}{|l|}{ IV } \\
\hline \multicolumn{6}{|l|}{ Race } \\
\hline & White & & 87.9 & $1,179,973$ & \\
\hline & Black & & 12.1 & 206,449 & \\
\hline Education & & $\begin{array}{l}12.9 \\
(2.9)\end{array}$ & & & $0-18$ \\
\hline Age & Age in years & $\begin{array}{r}48.3 \\
(15.5)\end{array}$ & & & $25-84$ \\
\hline \multicolumn{6}{|l|}{ Control } \\
\hline \multicolumn{6}{|l|}{ Sex } \\
\hline & Male & & 46.5 & 645,041 & \\
\hline & Female & & 53.5 & 741,381 & \\
\hline $\begin{array}{l}\text { Birth } \\
\text { Cohort }\end{array}$ & Year of birth & $\begin{array}{r}1960.7 \\
(17.0)\end{array}$ & & & $1898-1984$ \\
\hline \multicolumn{6}{|l|}{ Region } \\
\hline & Northeast & & 20.8 & 287,785 & \\
\hline & Cent/Mid West & & 26.3 & 364,839 & \\
\hline & South & & 35.5 & 488,807 & \\
\hline & West & & 17.7 & 244,991 & \\
\hline
\end{tabular}


Figure 2. Race and Health

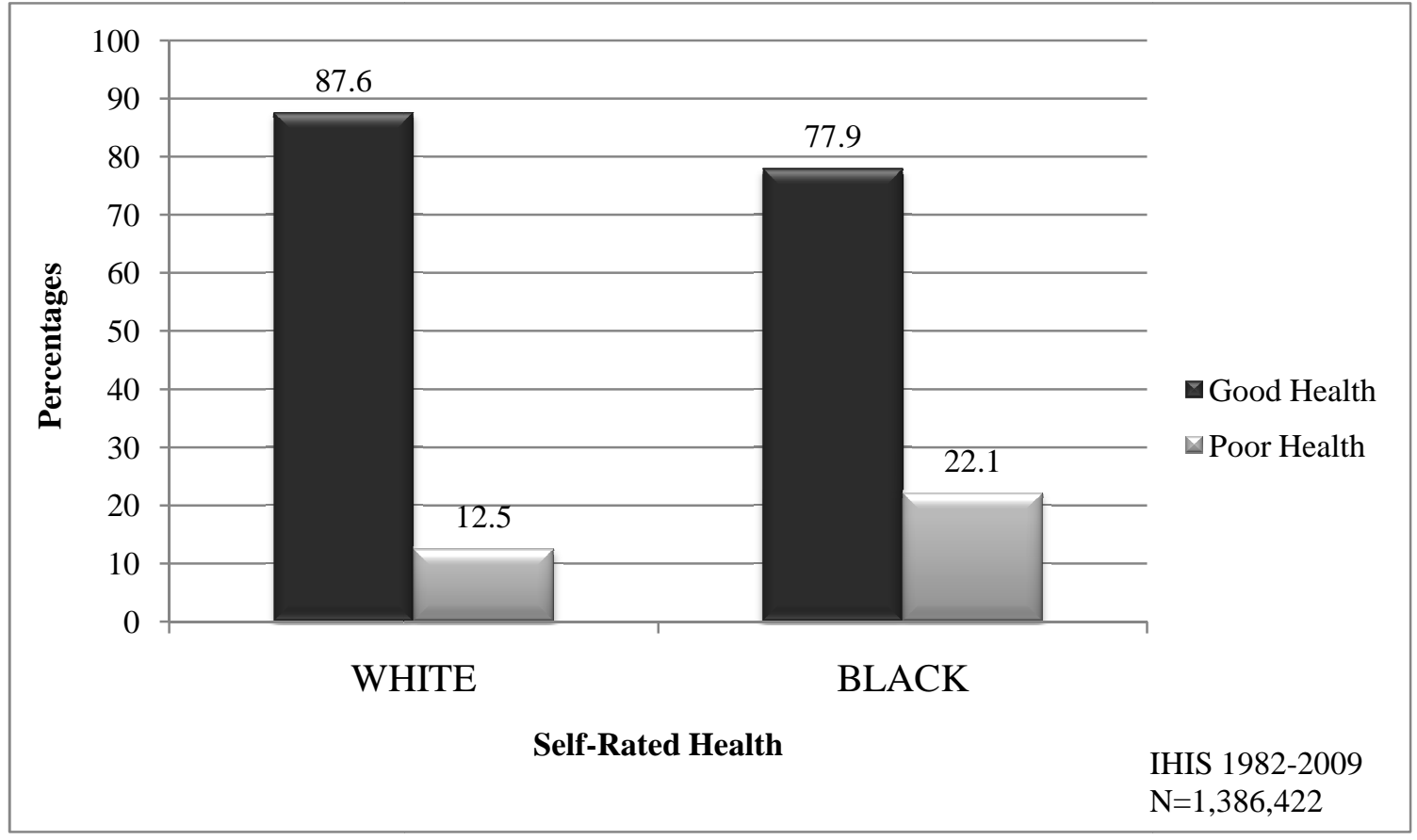

Figure 3. Race and Education

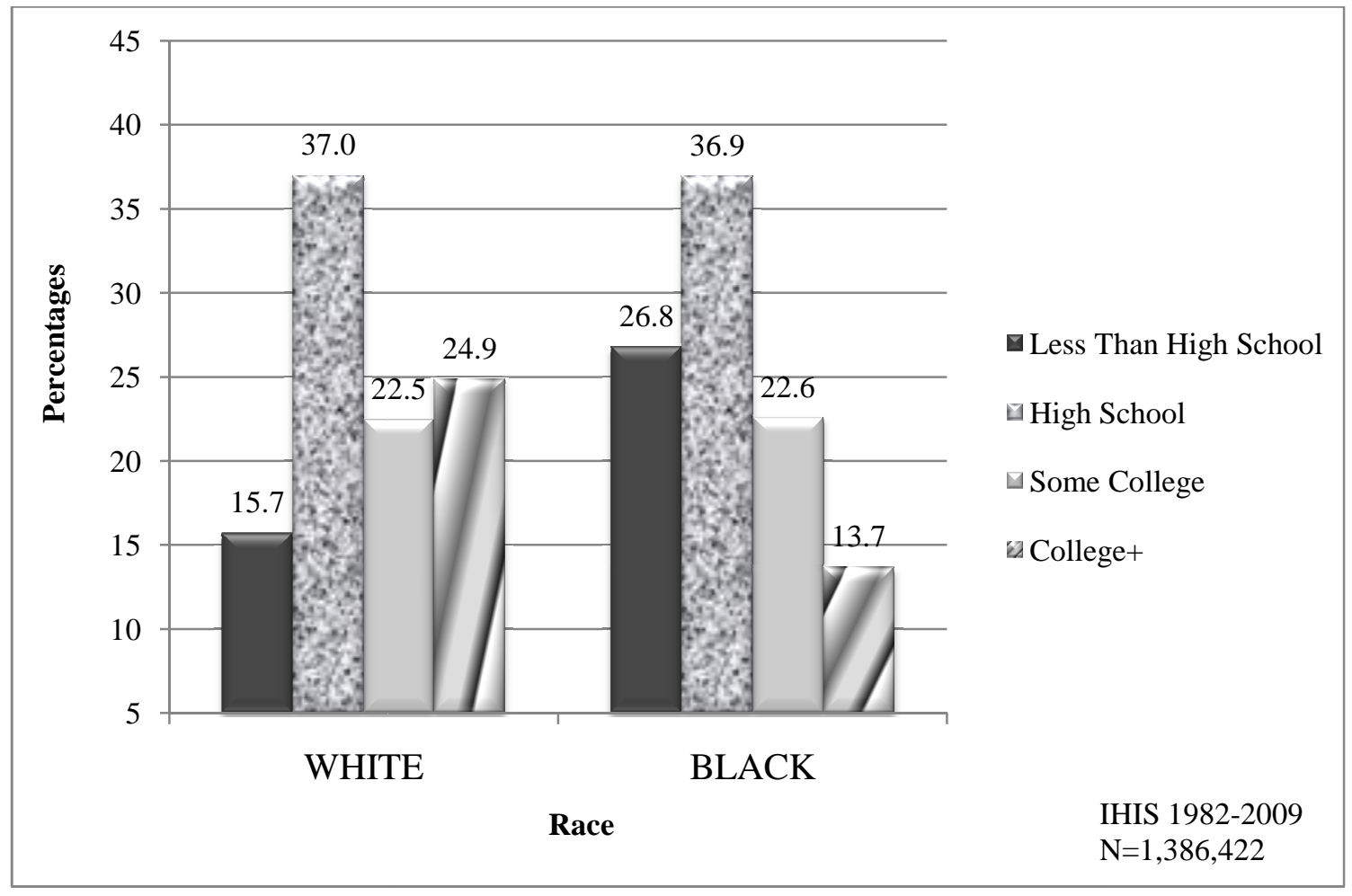


Figure 4. Racial Differences in Health by Level of Education

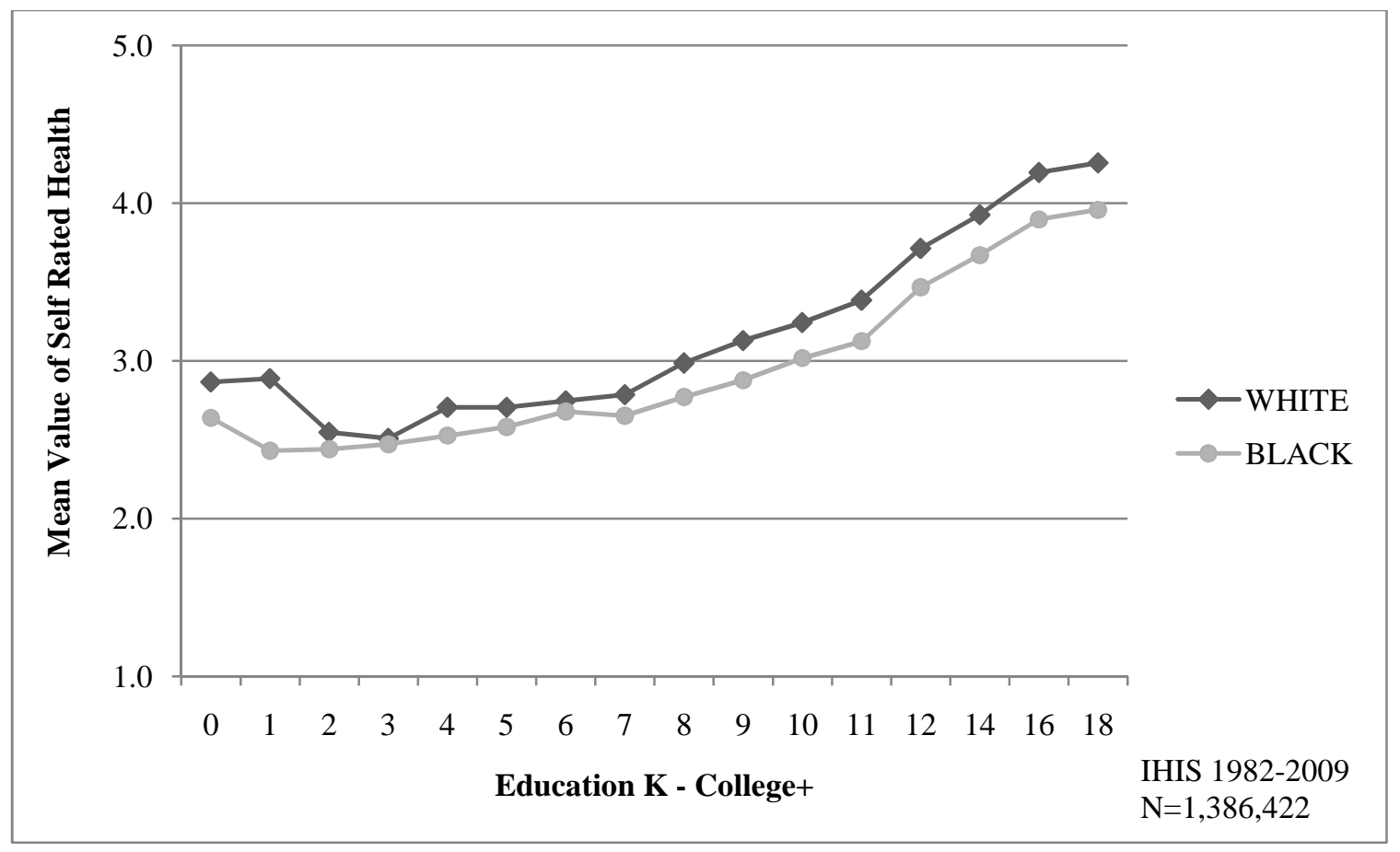

Figure 5. Racial Differences in Level of Education by Age

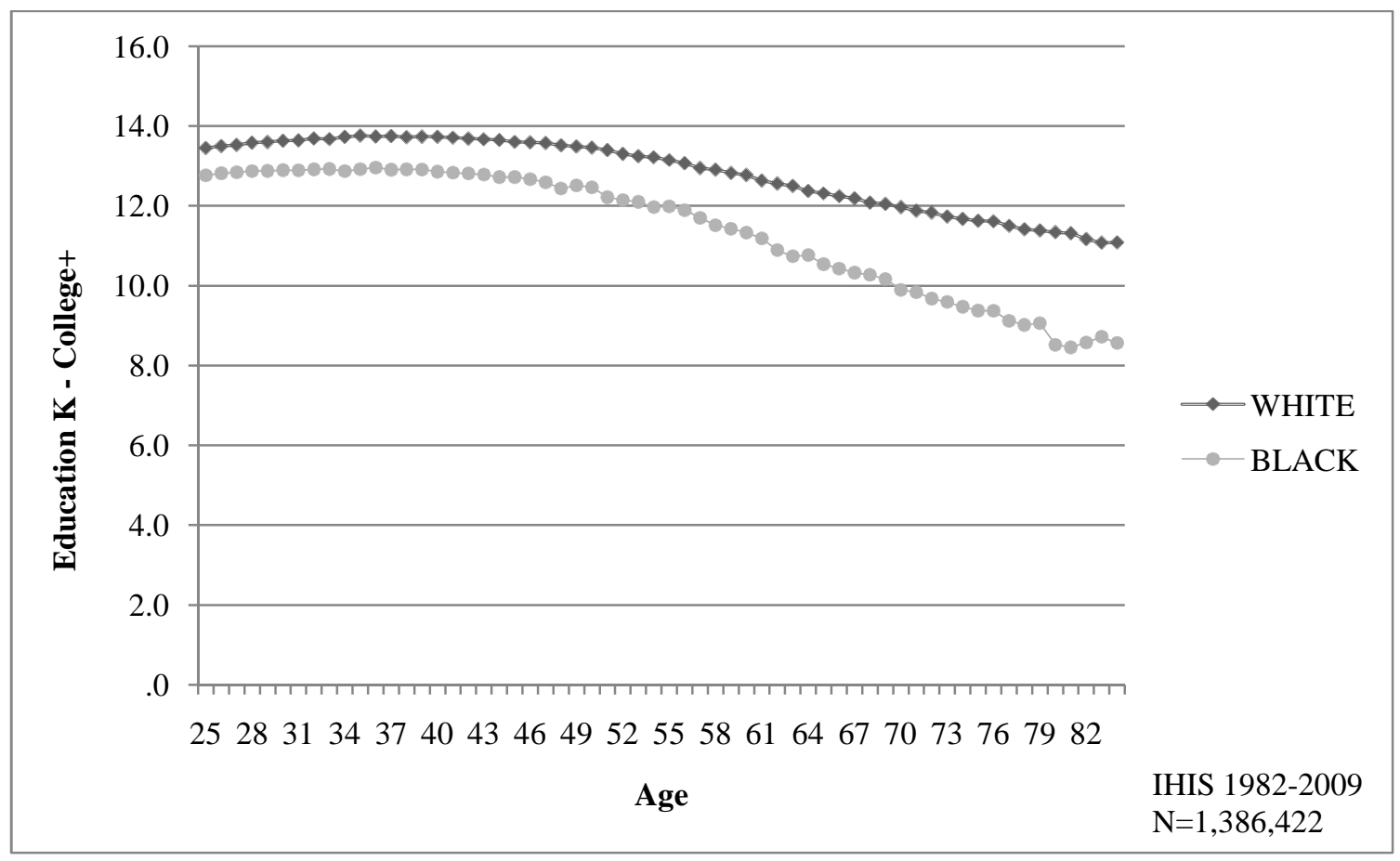




\begin{tabular}{|c|c|c|c|c|c|c|c|c|c|c|c|c|}
\hline \multirow[t]{2}{*}{ Variables } & \multicolumn{2}{|c|}{ Model 1} & \multicolumn{2}{|c|}{ Model 2} & \multicolumn{2}{|c|}{ Model 3} & \multicolumn{2}{|c|}{ Model 4} & \multicolumn{2}{|c|}{ Model 5} & \multicolumn{2}{|c|}{ Model 6} \\
\hline & B (S.E.) & OR & B (S.E.) & OR & B (S.E.) & OR & B (S.E.) & OR & B (S.E.) & OR & B (S.E.) & OR \\
\hline Black & $\begin{array}{l}-.640 \\
(.007)^{* * * *}\end{array}$ & 0.527 & $\begin{array}{c}-.583 \\
(.007)^{* * *}\end{array}$ & 0.558 & $\begin{array}{c}.029 \\
(.026)\end{array}$ & 1.029 & $\begin{array}{c}-.764 \\
(.014)^{* * *}\end{array}$ & 0.466 & $\begin{array}{l}-.588 \\
(.007)^{* * *}\end{array}$ & 0.555 & $\begin{array}{l}-.032 \\
(.063)\end{array}$ & 0.969 \\
\hline Education & $\begin{array}{l}.194 \\
(.001) * * *\end{array}$ & 1.214 & $\begin{array}{c}.196 \\
(.001)^{* * *}\end{array}$ & 1.217 & $\begin{array}{c}.206 \\
(.001)^{* * *}\end{array}$ & 1.229 & $\begin{array}{l}.197 \\
(.001)^{* * *}\end{array}$ & 1.218 & $\begin{array}{c}.306 \\
(.002)^{* * *}\end{array}$ & 1.358 & $\begin{array}{c}.317 \\
(.002)^{* * *}\end{array}$ & 1.373 \\
\hline Age & $\begin{array}{l}-.037 \\
(.000) * * *\end{array}$ & 0.964 & $\begin{array}{c}-.077 \\
(.002)^{* * *}\end{array}$ & 0.926 & $\begin{array}{c}-.076 \\
(.002)^{* * *}\end{array}$ & 0.927 & $\begin{array}{l}-.078 \\
(.002) * * *\end{array}$ & 0.925 & $\begin{array}{l}-.056 \\
(.002)^{* * *}\end{array}$ & 0.946 & $\begin{array}{l}-.055 \\
(.002)^{* * *}\end{array}$ & 0.946 \\
\hline $\operatorname{Age}^{\wedge} 2$ & & & $\begin{array}{c}.001 \\
(.000)^{* * *}\end{array}$ & 1.001 & $\begin{array}{c}.001 \\
(.000)^{* * *}\end{array}$ & 1.001 & $\begin{array}{c}.001 \\
(.000)^{* * *}\end{array}$ & 1.001 & $\begin{array}{c}.001 \\
(.000)^{* * *}\end{array}$ & 1.001 & $\begin{array}{c}.001 \\
(.000)^{* * *}\end{array}$ & 1.001 \\
\hline Female & & & $\begin{array}{c}-.054 \\
(.005)^{* * *}\end{array}$ & 0.947 & $\begin{array}{c}-.051 \\
(.005)^{* * *}\end{array}$ & 0.950 & $\begin{array}{l}-.053 \\
(.005)^{* * *}\end{array}$ & 0.948 & $\begin{array}{l}-.055 \\
(.005)^{* * *}\end{array}$ & 0.946 & $\begin{array}{l}-.052 \\
(.005)^{* * *}\end{array}$ & 0.949 \\
\hline Birth Cohor & & & $\begin{array}{c}-.004 \\
(.001)^{* * *}\end{array}$ & 0.996 & $\begin{array}{c}-.003 \\
(.001)^{* * *}\end{array}$ & 0.997 & $\begin{array}{l}-.003 \\
(.001)^{* * *}\end{array}$ & 0.997 & $\begin{array}{l}-.011 \\
(.001)^{* * *}\end{array}$ & 0.989 & $\begin{array}{l}-.010 \\
(.001)^{* * *}\end{array}$ & 0.990 \\
\hline Age*Cohort & & & $\begin{array}{c}.000 \\
(.000)^{* *}\end{array}$ & 1.0 & $\begin{array}{c}.000 \\
(.000)\end{array}$ & 1.0 & $\begin{array}{l}.000 \\
(.000)\end{array}$ & 1.0 & $\begin{array}{c}.000 \\
(.000)^{* * *}\end{array}$ & 1.0 & $\begin{array}{c}.000 \\
(.000)^{* * *}\end{array}$ & 1.0 \\
\hline Northeast & & & $\begin{array}{c}.389 \\
(.007)^{* * *}\end{array}$ & 1.476 & $\begin{array}{c}.392 \\
(.007)^{* * *}\end{array}$ & 1.480 & $\begin{array}{c}.389 \\
(.007)^{* * *}\end{array}$ & 1.476 & $\begin{array}{c}.383 \\
(.007)^{* * *}\end{array}$ & 1.467 & $\begin{array}{l}.387 \\
(.007)^{* * *}\end{array}$ & 1.473 \\
\hline Cen/Midwes & & & $\begin{array}{c}.232 \\
(.007)^{* * *}\end{array}$ & 1.261 & $\begin{array}{c}.235 \\
(.007)^{* * *}\end{array}$ & 1.265 & $\begin{array}{c}.232 \\
(.007)^{* * *}\end{array}$ & 1.261 & $\begin{array}{c}.227 \\
(.007)^{* * *}\end{array}$ & 1.255 & $\begin{array}{l}.229 \\
(.007)^{* * *}\end{array}$ & 1.257 \\
\hline West & & & $\begin{array}{c}.165 \\
(.008)^{* * *}\end{array}$ & 1.179 & $\begin{array}{c}.163 \\
(.008)^{* * *}\end{array}$ & 1.177 & $\begin{array}{l}.164 \\
(.008)^{* * *}\end{array}$ & 1.178 & $\begin{array}{c}.166 \\
(.008) * * *\end{array}$ & 1.181 & $\begin{array}{l}.164 \\
(.008)^{* * *}\end{array}$ & 1.178 \\
\hline Black * Edu & cation & & & & $\begin{array}{c}-.054 \\
(.002)^{* * *}\end{array}$ & 0.947 & & & & & $\begin{array}{l}-.050 \\
(.005)^{* * *}\end{array}$ & 0.951 \\
\hline Black * Age & & & & & & & $\begin{array}{c}.007 \\
(.000)^{* * *}\end{array}$ & 1.007 & & & $\begin{array}{c}.003 \\
(.002)\end{array}$ & 1.003 \\
\hline Education * & Age & & & & & & & & $\begin{array}{l}-.003 \\
(.000)^{* * * *}\end{array}$ & 0.997 & $\begin{array}{l}-.003 \\
(.000)^{* * *}\end{array}$ & 0.997 \\
\hline Black * Edu & cation * Age & & & & & & & & & & $\begin{array}{l}.000 \\
(.000)\end{array}$ & 1 \\
\hline Constant & $\begin{array}{l}.558 \\
(.013)^{* *}\end{array}$ & 1.747 & $\begin{array}{l}1.003 \\
(.055)^{* *}\end{array}$ & 2.726 & $\begin{array}{c}.838 \\
(.055)^{* * *}\end{array}$ & 2.312 & $\begin{array}{l}1.020 \\
(.055)^{* * *}\end{array}$ & 2.77 & $\begin{array}{l}.127 \\
(.057)^{* *}\end{array}$ & 1.135 & $\begin{array}{l}-.037 \\
(.059) \\
\end{array}$ & 0.964 \\
\hline$-2 \mathrm{LL}$ & $1.010 \mathrm{E} 6$ & & $1.004 \mathrm{E} 6$ & & $1.004 \mathrm{E} 6$ & & 1.004E6 & & $1.001 \mathrm{E} 6$ & & $1.001 \mathrm{E} 6$ & \\
\hline
\end{tabular}


Figure 6. Model 3: Racial Differences in the Effect of Education on Health.

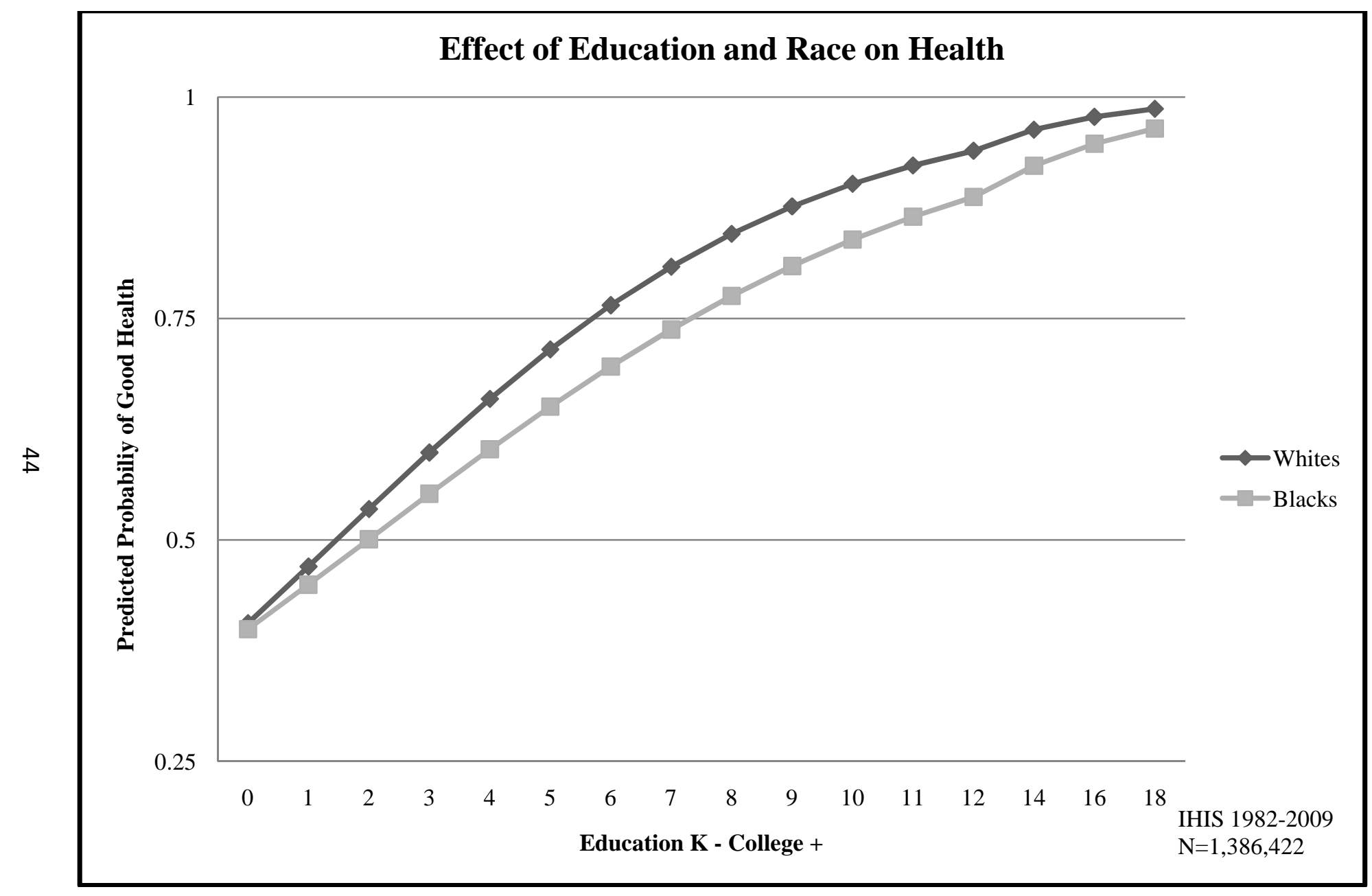


Figure 7. Model 4: Racial Differences in the Effect of Age on Health.

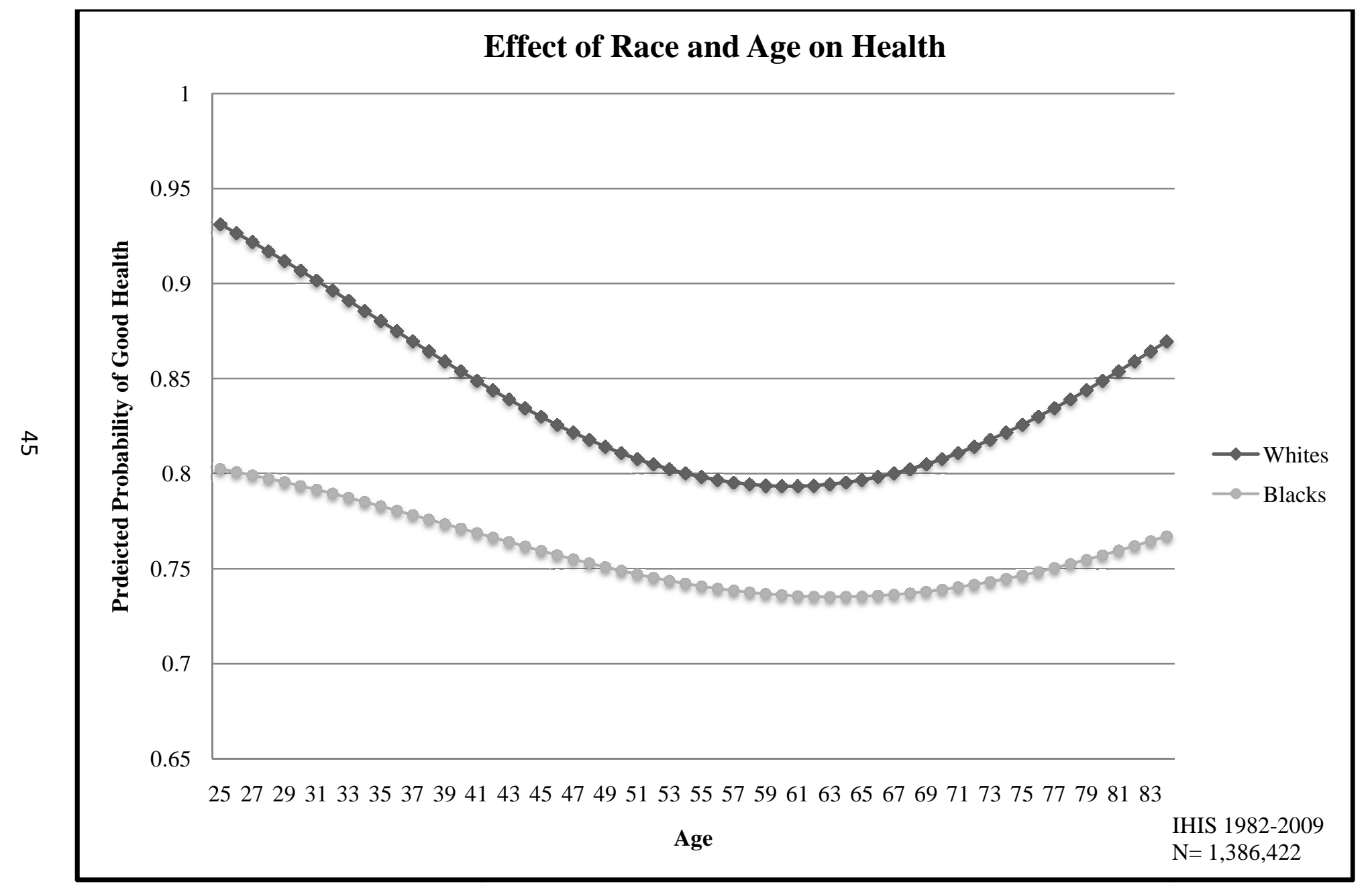


Figure 8a. Model 5: Education-Health Disparity Over the Life-Course: Whites

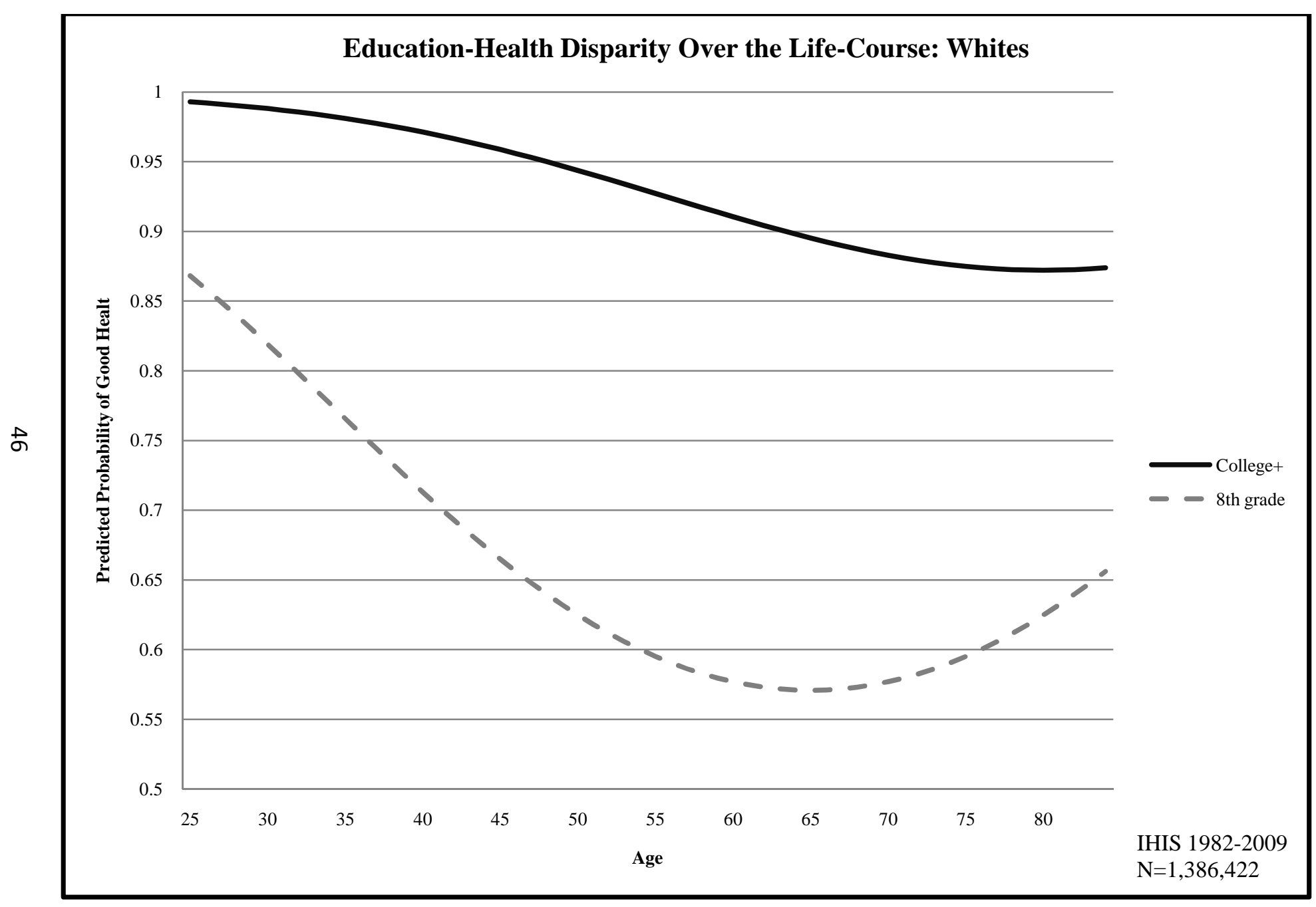


Figure 8b. Model 5: Education-Health Disparity Over the Life-Course: Blacks

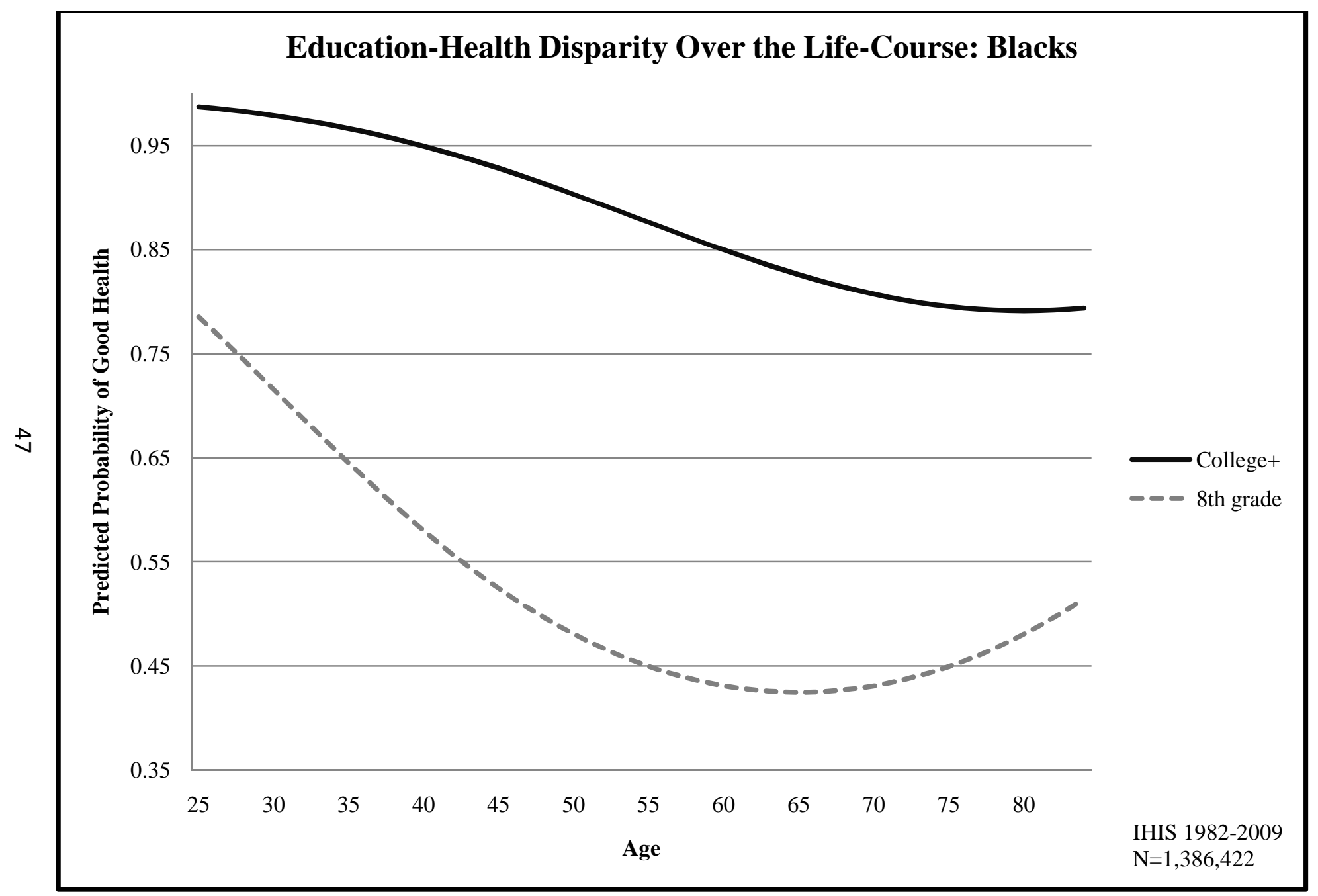


Figure 9a. Model 5: The Effect of Education on Health over the Life-Course for Low Levels of Education

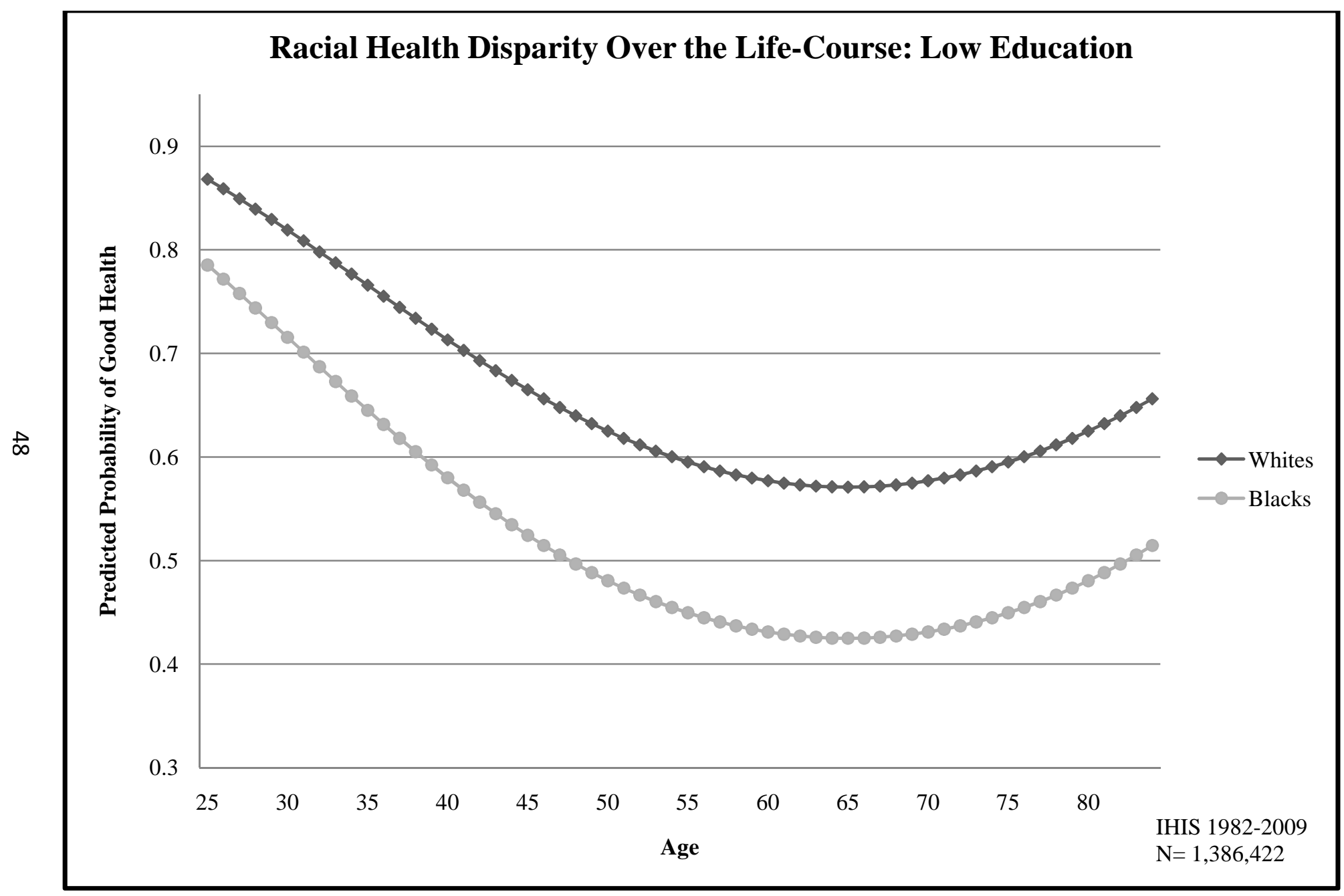


Figure 9b. Model 5: The Effect of Education on Health over the Life-Course for High Levels of Education

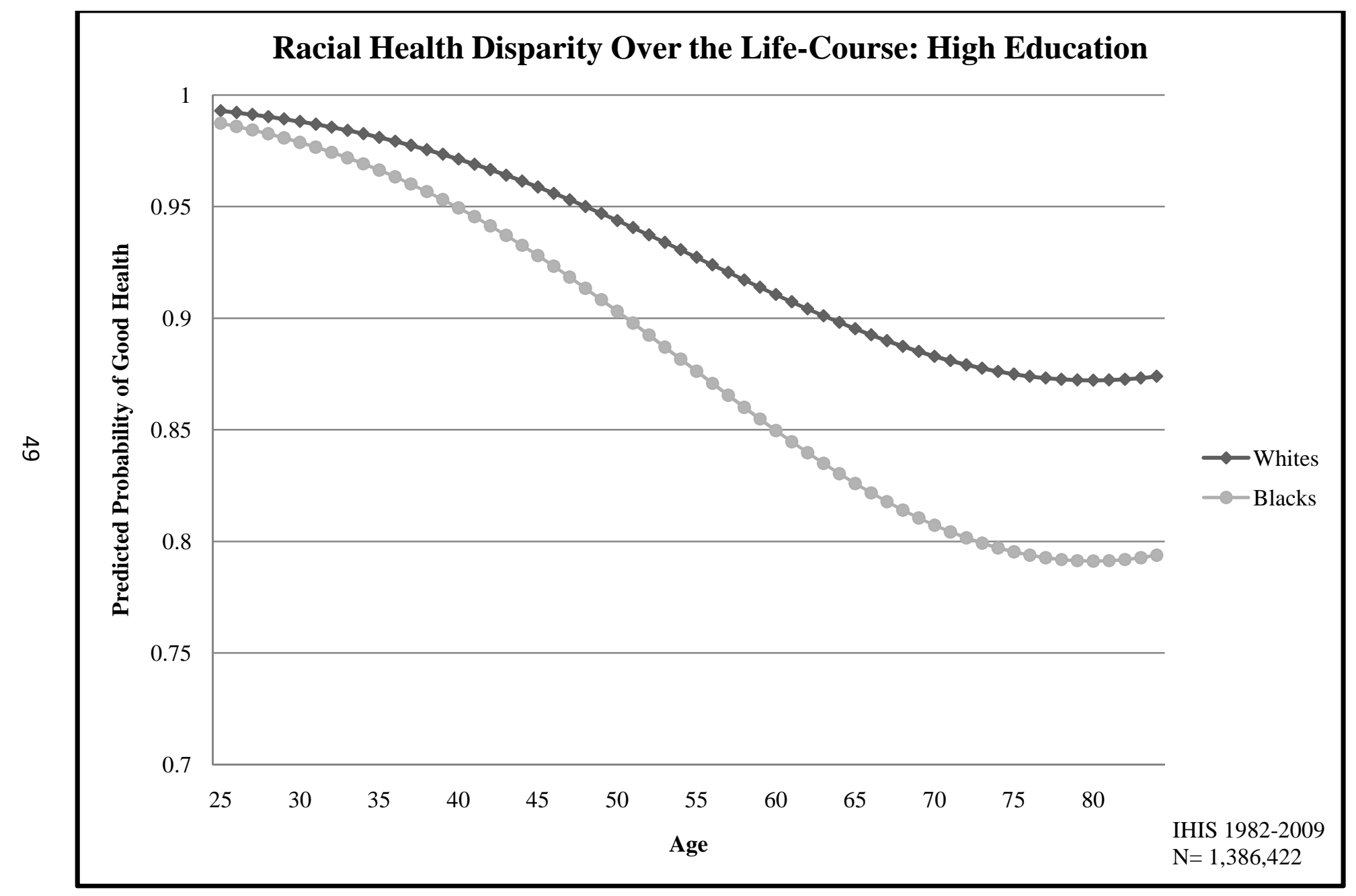




\section{DiscuSSION}

\section{Racial Differences in the Effect of Education on Health}

This research aimed to examine racial differences in the effects of education on health as a possible factor influencing the black/white health disparity. Education can play a role in shaping the racial health disparity both because the groups receive different levels of education and due to a racial disparity in the positive effect of education on health. For this reason it is important to know whether or not blacks receive the same education returns on their overall health as do whites. Previous research has demonstrated that blacks do not receive the same health returns for higher SES achievement as do whites (Farmer and Ferraro, 2005). The first hypothesis of this research addressed this question in terms of health returns on education in particular and predicted that the positive effect of education on health would be greater for whites than for blacks.

As my first hypothesis predicted and in accordance with previous research, blacks were shown to receive lower education returns on their overall health than whites. While attaining higher levels of education is shown to increase likelihood of having good health for both blacks and whites, the positive effect of education on health is stronger for whites. There are a couple of possible reasons for this. First, there is evidence that in general blacks receive poorer quality education than whites (Card, 1992). The disparity in health returns on education between blacks and whites could be partially due to the disparity in quality of education. Also, scholars have argued that controlling for the indirect effects of racial discrimination through level of education, may not fully take into 
account the more direct effects that racism can have on health, for example, as it structures neighborhood segregation and unequal health care (Williams, 1999). Racial neighborhood segregation can result in racial minorities experiencing less access to services, more exposure to environmental hazards and toxins as well as poor-quality housing conditions and increased violence (Collins and Williams, 1999). Additionally, there is evidence that even after controlling for income level and patient's insurance status, racial minorities tend to receive poorer quality health care and treatment (Smedley et al., 2002). Lastly, some research suggests that the subjective experience of racial discrimination can have negative effects on both mental and physical health (Williams and Chung, 1999). The findings of this research, that blacks receive lower health returns on education than whites, may be explained by the lower quality education that blacks receive and the added negative effects of racial discrimination on health.

\section{Education-Health Disparity and the Life-Course}

An analysis of the effect of education on health over the life-course allows for a more in-depth understanding of the nature of the relationship between educational attainment and health. As my second hypothesis predicted and in accordance with the mortality-as-leveler hypothesis, the effect of education on health, for both blacks and whites, was shown to grow over the life-course resulting in the widening of the gap in levels of health between the highly educated and the poorly educated. Furthermore, as my second hypothesis predicted, the probability of having good health was shown to have a non-linear pattern over the life-course. For both blacks and whites, the probability of having good health declined over the life-course until around age 60 when it leveled out 
and eventually began to increase slightly around age 80 . The findings of this research clearly support the mortality-as-leveler hypothesis and corroborate previous research that suggested that the effect of education on health grows over the life-course (Lynch, 2003; Ross and $\mathrm{Wu}, 1996)$ and that the education-health disparity begins to level and eventually diminish at the end of the life-course (Christenson,1995; Dupre, 2007).

\section{Racial Differences in the Effect of Education over the Life-Course}

The effect of education on health over the life-course is similar for blacks and whites. However, blacks have lower levels of health at every age and every level of education and the racial health disparity operates differently across education groups. The third hypothesis of this research is only partially supported. In general there is no significant racial difference in the effect of education on health over the life-course. However, the racial disparity in health does appear to grow over the life-course among the highly educated. These findings are not surprising when one considers the lower health returns on education received by blacks. A possible explanation for both the lower health returns on education received by blacks and the fact that the racial health disparity among the highly educated grows over the life-course could be that while higher levels of education result in increased opportunities for whites, highly educated blacks are not afforded the same opportunities. In other words, the mechanisms which link education to health, such as work and economic conditions or social-psychological resources, may operate less effectively for highly educated blacks who face structural barriers such as racial discrimination. 


\section{CONCLUSION}

Racial and socioeconomic inequalities, especially when they manifest as health disparities and lives lost, are unacceptable. The complex relationships between race and education and age that shape and determine health disparities require continued attention and research. This research has contributed to the growing body of literature regarding the nature of black/white health disparities in the U.S. The findings of this research (1) show that blacks do not receive the same health returns on their education as whites, (2) support the mortality-as-leveler hypothesis in that the effect of education grows over the life-course, and that there is eventually a narrowing of education-health disparities at later life stages, and (3) show that the racial health disparity grows over the life course for the highly educated and stays consistent for the poorly educated. These patterns shed light on the interaction effects of race and SES on health over the life-course and indicate that these complex relationships continues to pattern the distribution of disease and illness.

The findings of this research suggest that education is an essential avenue for addressing racial health disparities. Although racial health disparities persist within every level of education a large part of the inequality could be due to a disparity in the quality of education received. Addressing racial education disparities, both in terms of level and quality attained would reduce racial disparities in health. Furthermore, the fact that the racial health disparity grows among the highly educated over the life-course implies that highly educated blacks continue to face structural barriers. Ultimately, in order to close the racial gap in health outcomes, racial discrimination in the U.S. must be addressed. In addition to the education system, addressing racial discrimination in the housing and job 
markets as well as in the health care system would have a great positive effect on minority health outcomes.

Finally, this research is not without limitations. First, although the findings do support the mortality-as-leveler hypothesis, without longitudinal data selective mortality cannot be controlled for. While it is hard to imagine another occurrence responsible for the increased probability of good health in the later life stages, this research does not actually test for selective mortality and therefore cannot make any conclusions about the presence of the phenomenon. Additionally, the instrument used to measure education was continuous and as such does not account for the possibility that health is more affected by receiving the credentials associated with the completion of a degree than by every additional year of education. Future research should explore these patterns using longitudinal data in order to control for the selective mortality phenomenon as well as the possibility that health is affected by education through credentialism. 


\section{REFERENCES}

Adler, Nancy E., Thomas Boyce, Margaret A Chesney, Sheldon Cohen, Susan Folkman, Robert L. Kahn, and S. Leonard Syme. 1994 "Socioeconomic Status and Health: The Challenge of the Gradient." American Psychologist, 49:15-24.

American Cancer Society. 2008. "Cancer Facts \& Figures 2008.” American Cancer Society, 1-72.

American Society of Clinical Oncology. 2009. "Health Disparities in the United States: Facts And Figures." American Society of Clinical Oncology, 1-3.

Antonovsky, Aaron. 1967. "Social Class, Life Expectancy and Overall Mortality." Milbank Memorial Fund Quarterly, 45:31-73.

Beckett, Megan. 2000. "Converging Health Inequalities in Later Life - An Artifact of Mortality Selection?” Journal of Health and Social Behavior, 41:106-119.

Braveman, Paula. 2006. "Health Disparities and Health Equity: Concepts and Measurement." Annual Review Public Health, 27:167-194.

Buck, Carol W. 1981. "Prenatal and Perinatal Causes of Early Death and Defect." Pp. 149-166 in Preventative and Community Medicine, 2d ed., edited by D.W. Clark and B. MacMahon. Boston, MA: Little, Brown, and Company.

Card, David and A.B. Krueger. 1992. "Does School Quality Matter? Returns to Education and the Characteristics of Public Schools in the United States." Journal of Political Economy, 100(1):1-40.

Card, David. 1999. "The Causal Effect of Education on Earnings." In Handbook of Labor Economics, vol. 3A, Orley Ashenfelter, and David Card, eds. Amsterdam: Elsevier Science/North-Holland.

Chandola, Tarani and Crispin Jenkinson. 2000. "Validating Self-Rated Health in Different Ethnic Groups.” Ethnicity \& Health, 5:151-9.

Christenson, Bruce A. 1995. "Educational Inequality in Adult Mortality: An Assesment with Death Certificate of Data from Michigan." Demography, 32:215-229.

Clark, Daniel O., and George L. Maddox. 1992. "Racial and Social Correlates of Age Related Changes in Functioning." Journal of Gerontology, 47:S222-S232. 
Coburn, David and Clyde R. Pope. 1974. "Socio-economic Status and Preventive Health Behavior." Journal of Health and Social Behavior, 15:67-78.

Collins, Chiquita A. and David R. Williams. 1999. "Segregation and Mortality: The Deadly Effects of Racism?" Social Forum, 14(3):493-521.

Collins, Patricia H. 2000. Black Feminist Thought: Knowledge, Consciousness, and the Politics of Empowerment. New York: Routledge.

Crimmins, Eileen M. and Yasuhiko Saito. 2001. "Trends in Healthy Life Expectancy in the United States, 1970-1990: Gender, Racial, and Educational Differences." Social Science \& Medicine, 52(11):1629-1641.

Dalstra J. A. A., A. E. Kunst, C. Borrell, E. Breeze, E. Cambois, G. Costa, J. J. M. Geurts, E. Lahelma, H. Van Oyen, N. K. Rasmussen, E. Regidor, T. Spadea, J. P. Mackenbach. 2005. "Socioeconomic Differences in the Prevalence of Common Chronic Diseases: an Overview of Eight European Countries. International Journal of Epidemiology, 34(2):316-326.

Darrow, Sherri L., Marcia Russell, M. Lynne Copper, Pamela Mudar, and Michael R. Frone. 1992. "Sociodemographic Correlates of Alcohol Consumption Among African-American and White Women." Women and Health, 18: 35-51.

Doornbos, G and D. Kromhout. 1990. "Educational Level and Mortality in a 32-year Follow-Up Study of 18-Year-Old Men in the Netherlands." International Journal of Epidemiology, 19:374-379.

Dupre, Matthew E. 2007. "Educational Differences in Age-Related Patterns of Disease: Reconsidering the Cumulative Disadvantage and Age-As-Leveler Hypotheses." Journal of Health and Social Behavior, 48:1-15.

Dutton, Diana B. 1986. "Social Class Health, and Ilness." Pp. 31-62 in Applications of Social Science to Clinical Medicine and Health Policy, edited by L Aiken and D. Mechanic. New Brunswick, NJ: Rutgers University Press.

Eckenrode, John. 1983. "The Mobilization of Social Supports: Some Individual Constraints." American Journal of Community Psychology, 11:509-528.

Elo, Irma T., Samuel H Preston. 1996. "Educational Differentials in Mortality: United States, 1979-85." Social Science \& Medicine, 42(1):47-57.

Farmer, Melissa M. and Kenneth F. Ferraro. 2004. "Are Racial Disparities in Health Conditional on Socioeconomic Status?" Social Science \& Medicine, 60:194-204. 
Ferraro, Kenneth F., Melissa M. Farmer and John A. Wybraniec. 1997. "Health Trajectories: Long-Term Dynamics Among Black and White Adults." Journal of Health and Social Behavior, 38:38-54.

Ford, Earl S., Robert K. Merritt, Gregory W. Heath, Kenneth E. Powell, Richard A. Wash-burn, Andrea Kriska, and Gwendolyn Haile. 1991. "Physical Activity Behaviors in Lower and Higher Socioeconomic Status Populations." American Journal of Epidemiology, 133:1246-55.

Fox, A. J., Goldblatt P.O., Jones D. R. 1985 “Social Class Mortality Differentials: Artifact, Selection, or Life Circumstances?" Journal of Epidemiology and Community Health, 39:1-8.

Freedman, Vicki A. and Linda G. Martin. 1999. "The Role of Education in Explaining and Forecasting Trends in Functional Limitations Among Older Americans." Demography, 36(4):461-473.

Freid, V., K. Prager, A. MacKay and H. Xia. 2003. Chartbook on Trends in the Health of Americans, Health, United States, 2003. Hyattsville, Maryland: National Center for Health Statistics.

Fuller-Thomas, Esme, Amani Nuru-Jeter, Meredith Minkler and Jack M. Guralnik. 2009. "Black-White Disparities in Disability Among Older Americans: Further Untangling the Role of Race and Socioeconomic Status." Journal of Aging and Health, 21:677-698.

Farmer, Melissa M. and Kenneth F. Ferraro. 2005. "Are Racial Disparities in Health Conditional on Socioeconomic Status?” Social Science \& Medicine, 60:191-204.

Helmert U., B. Herman, K.-H. Joeckel, E. Greiser, and J. Madans. 1989. "Social Class and Risk Factors for Coronary Heart Disease in the Federal Republic of Germany. Results of the Baseline Survey of the German Cardiovascular Prevention Study." Journal of Epidemiology and Community Health, 43:37-42.

House, James S., Ronald C. Kessler, and A. Regula Herzog. 1990. “Age, Socioeconomic Status, and Health.” Milbank Memorial Quarterly, 68:383-411.

House, James S., James M. Lepkowski, Ann M. Kinney, Richard P. Mero, Ronald C. Kessler, and A Regula Jerzog. 1994. "The Social Stratification of Aging and Health." Journal of Health and Social Behavior, 35:213-234.

Hughes, Michael and Melvin E. Thomas. 1998. "The Continuing Significance of Race Revisited: A Study of Race, Class, and Quality of Life in America, 1972 to 1996." American Sociological Review, 63:785-795. 
Huisman M., A. E. Kunst, M. Bopp, B. K. Borgan, C. Borrell, G. Costa, P. Deboosere, S. Gadeyne, M. Glickman, C. Marinacci, C. Minder, E. Regidor, T. Valkonen, J. P. Mackenbach. 2005. "Educational Inequalities in Cause-Specific Mortality in Middle-Aged and Older Men and Women in Eight Western European Populations. Lancet, 365(9458):493-500.

Illsley, Raymond and Ken Mullen. 1985. “The Health Needs of Disadvantaged Client Groups." Pp. 389-402 in Oxford Textbook of Public Health, edited by W.W. Holland, R. Detels, and G. Knox. Oxford, England: Oxford University Press.

Jackson, J. J. 1985. "Race, National Origin, Ethnicity, and Aging." Pp. 246-303 In Handbook of Aging and the Social Sciences, edited by Robert H. Binstock, and Ethel Shanas. New York: Van Nostrand Reinhold.

Jacobsen, Bjarne K. and Dag S. Thelle. 1988. "Risk Factors for Coronary Heart Disease and Level of Education." American Journal of Epidemiology, 127:923-32.

Kelly-Moore, Jessica A. and Kenneth F. Ferraro. 2004. "The Black/White Disability Gap: Persistent Inequality in Later Life?” Journal of Gerontology, 59:S34-S43.

Kessler, Ronald C. and Jane D McLeod. 1985. "Social Support and Mental Health in Community Samples." Pp. 219-240 in Social Support and Health, edited by S. Cohen and S. L. Syme. New York: Academic.

Kitagawa, Evelyn M. and Philip M. Hauser. 1973. Differential Mortality in the United States: A Study in Socioeconomic Epidemiology. Cambridge, MA: Harvard University Press.

LaRocco, Jame M., James S. House, and John R P. French. 1980. "Social Support, Occupational Stress, and Health." Journal of Health and Social Behavior, 3:202218.

LaVeist, Thomas A. 1994. "Beyond Dummy Variables and Sample Selection: What Health Services Researchers Ought to Know About Race as a Variable." Health Services Research, 29:1-16.

LaVeist, Thomas A. 2005a. "Disentangling Race and Socioeconomic Status: A Key to Understanding Health Inequalities." Journal of Urban Health: Bulletin of the New York Academy of Medicine, 82(2):iii26-iii34.

LaVeist, Thomas A. 2005b. Minority Populations and Health: An Introduction to Health Disparities in the United States. San Francisco: Jossey-Bass. 
LaVeist, Thomas A., Roland J. Thorpe Jr., GiShawn A. Mance, and John Jackson. 2007. "Overcoming Confounding of Race with Socio-Economic Status and Segregation to Explore Race Disparities in Smoking." Addiction, 102(Suppl. 2):65-70.

Liberatos, Penny, Bruce G. Link and Jennifer L. Kelsey. 1988. "The Measurement of Social Class in Epidemiology." Epidemiologic Reviews, 10: 87-121.

Lillie-Blanton, Marsha and Thomas A. LaVeist. 1996. "Race/Ethnicity, the Social Environment, and Health." Social Science \& Medicine, 43(1):83-91.

Link, Bruce G., and Jo Phelan. 1995. "Social Conditions As Fundamental Causes of Disease." Journal of Health and Social Behavior, 35: 80-94.

Liu, Kiang, Lucilia B. Cedres, Jeremiah Stamler, Alan Dyer, Rose Stamler, Serafin Nanas, David M. Berkson, Oglesby Paul, Mark Lepper, Howard A. Lindberg, John Marquar, Elizabeth Stevens, James A. Schoenberger, Richard B. Shekelle, Patricia Collette, Sue Shekelle, and Dan Gardside. 1982. "Relationship of Education to Major Risk Factors and Death from Coronary Heart Disease, Cardiovascular Diseases, and All Causes." Circulation, 66:1308-14.

Lynch, Scot M. 2003. "Cohort and Life-Course Patterns in the Relationship between Education and Health: A Hierarchical Approach.” Demography, 40(2):309-331.

Markides, Kyriakos S. and Charles H. Mindel. 1987. Aging and Ethnicity. Newbury Park, CA: Sage Publications.

Marmot Michael G., H. Bosma, H. Hemingway, E. Brunner, S. Stansfeld. 1997. "Contribution of Job Control and Other Risk Factors to Social Variations in Coronary Heart Disease Incidence." Lancet, 350(9073):235-239.

Matthews, Karen A., Sheryl F. Kelsey, Elaine N. Meilahn, Lewis H. Kuller, and Rena R. Wing. 1989. "Educational Attainment and Behavioral and Biological Risk Factors for Coronary Heart Disease in Middle-Aged Women." American Journal of Epidemiology, 129:1132-44.

Mead, Holly, Lara Cartwright-Smith, Karen Jones, et al. 2008. "Racial and Ethnic Disparities in U.S. Health Care: A Chartbook." The Commonwealth Fund, 1111:1-113.

Merton, Robert K. 1968. “The Matthews Effect in Science.” Science, 159:56-63.

Midanik, Lorraine T., Arthur L. Klatsky, and Mary Anne Armstrong. 1990. "Changes in Drinking Behavior: Demographic, Psycho-social, and Biomedical Factors." International Journal of the Addictions, 25: 599-619. 
Millar, Wayne J. and Donald T. Wigle. 1986. "Socioeconomic Disparities in Risk Factors for Cardiovascular Disease." Canadian Medical Association Journal, 134:127-32.

Minkler Meredith, Fuller-Thomson Esme and Jack M. Guralnik. 2006 "Gradient of Disability Across the Socioeconomic Spectrum in the United States." New England Journal of Medicine, 355(7):695-703.

Mirowsky, John, and Catherine E. Ross. 2003. Education, Social Status and Health. Hawthorne, NY: Aldine de Gruyter.

Mutchler, Jan E. and Jeffrey A. Burr. 1991. "Racial Differences in Health and Health Care Service Utilization in Later Life: The Effect of Socioeconomic Status." Journal of Health and Social Behavior, 32:342-356.

National Center for Health Statistics. 2010. "Health, United States, 2009: With Special Feature on Medical Technology." National Center for Health Statistics, 1-574

Navarro, Vicente. 1991. "Class and Race: Life and Death Situations." Monthly Review, 43:1-13.

Ostchega, Yechiam, Tamara B. Harris, Rosemarie Hirsch, Van L. Parsons and Raynard Kington. 2000. "The Prevalence of Functional Limitations and Disability in Older Persons in the US: Data from the National Health And Nutrition Examination Survey III." Journal of the American Geriatrics Society, 48:11321135 .

Pamuk, E. 1998. Socioeconomic Status and Health Chartbook, Health United States, 1998. Hyattsville, MD: National Center for Health Statistics.

Pappas, Gregory, Susan Queen, Wilbur Hadden, and Gail Fisher. 1993. "The Increasing Disparity in Mortality Between Socioeconomic Groups in the United States. “ The New England Journal of Medicine, 329:103-109.

Pappas, Gregory. 1994. "Elucidating the Relationships Between Race, Socioeconomic Status, and Health." American Journal of Public Health, 84(6):892-893.

Pettigrew, Thomas F. 1981. "Race and Class in the 1980's: An Interactive View." Daedalus 110(2):233-255.

Power, C., O. Manor, A. J. Fox, and K. Fogelman. 1990. "Health in Childhood and Social Inequalities in Health in Young Adults." Journal of Royal Statistics Society, 153:17-28. 
Rodin, Judith and Christine Timko. 1992. "Sense of Control, Aging, Health." Pp. 207236 in Aging, Health, and Behavior, edited by M. G. Ory, R. P. Abeles and P. D. Lipman. Newbury Park, CA: Sage.

Rogers, Richard G., Robert A. Hummer, and Charles B. Nam. 2000. Living and Dying in the USA. San Diego: Academic Press.

Romelsjo, Anders and Finn Diderichsen. 1989. "Changes in Alcohol-Related Inpatient Care in Stockholm County in Relation to Socioeconomic Status During a Period of Decline in Alcohol Consumption." American Journal of Public Health, 79:5256.

Ross, Catherine E. and John Mirowsky. 1989. "Explaining the Social Patterns of Depression: Control and Problem Solving - or Support and Talking." Journal of Health and Social Behavior, 30:206-219.

Ross, Catherine E., and Chia-Ling Wu. 1995. "The Links Between Education and Health.” American Sociological Review, 60:719-745.

Ross, Catherine E., and Chia-Ling Wu. 1996. "Education, Age, and the Cumulative Advantage in Health." Journal of Health and Social Behavior, 37:104-120.

Rowe, John W. and Robert L. Kahn. 1987. "Human Aging: Usual and Successful." Science, 143:143-149.

Schnittker, Jason. 2004. "Education and the Changing Shape of the Income Gradient in Health." Journal of Health and Social Behavior, 45:286-305.

Schoenbaum, Michael and Timothy Waidmann. 1997. "Race, Socioeconomic Status, and Health: Accounting For Race Differences in Health.” Journal of Gerontology, 52B:61-73.

Shea, Steven, Aryeh D. Stein, Charles E. Basch, Rafael Lantingue, Christopher Maylahn, David S. Strogatz, and Lloyd Novick. 1991. "Independent Associations of Educational Attain-ment and Ethnicity with Behavioral Risk Factors for Cardiovascular Disease." American Journal of Epidemiology, 134:567-82.

Smedley, Brian D., Adrienne Y. Stith and Alan R. Nelson, eds. 2002. Unequal Treatment: Confronting Racial and Ethnic Disparities in Health Care. Institute of Medicine, Washington, DC: National Academy Press.

Thorpe, Roland J. Jr., Dwayne T. Brandon, and Thomas A. LaVeist. 2008. "Social Context as an Explanation for Race Disparities in Hypertension: Findings from 
the Exploring Health Disparities in Integrated Communities (EHDIC) Study." Social Science \& Medicine, 67:1604-1611.

Vargas, Clemencia M., Deborah D. Ingram, and Richard F. Gillum. 2000. "Incidence of Hypertension and Educational Attainment: The NHANES-I Epidemiologic Followup Study." American Journal of Epidemiology, 152(3):272-278.

Wagenknecht, Lynne E., Laura L. Perkins, Gary R. Cutler, Stephen Sidney, and Gregory L. Burke, Teri A. Manolia, David R. Jacobs, Kiang Liu, Gary D. Friedman, Glenn H. Hughes, and Stephen B. Hulley. 1990. "Cigarette Smoking is Strongly Related to Educational Status: the CARDIA Study." Preventive Medicine, 19:158-69.

Wilkinson, Richard G. 1986. Class and Health: Research and Longitudinal Data. London: Tavistock.

Williams, David R. and Chiquita A. Collins. 1995. "US Socioeconomic and Racial Differences in Health: Patterns and Explanations." Annual Review of Sociology, 21:349-386.

Williams, David R. 1999. "Race, Socioeconomic Status, and Health: The Added Effects of Racism and Discrimination." Annals of the New York Academy of Sciences, 89:173-88.

Williams, David R. and A-M Chung. 1999. "Racism and Health" in Health in Black America, edited by R. Gibson and J. S. Jakson, Thousand Oaks, CA: Sage Publications.

Williams David R. and Chiquita A. Collins. 2001. "Racial Residential Segregation: a Fundamental Cause of Racial Disparities in Health. Public Health Reports, 116:404-416.

Williams, David R. and Pamela Braboy-Jackson. 2005. Social Sources of Racial Disparities in Health." Health Affairs, 24:325-334.

Wilson, William J. 1980. The Declining Significance of Race: Blacks and Changing American Institutions. Chicago: University of Chicago Press.

Winkleby, Marilyn A., Darius E. Jatulis, Erica Frank, and Stephen P. Fortmann. 1992. "Socio-economic Status and Health: How Education, Income, and Occupation Contribute to Risk Factors for Cardiovascular Disease." American Journal of Public Health, 82:816-20.

World Health Organization. 2011. "Glossary of Terms." Health Impact Assessment. Retrieved February 8, 2011 (http://www.who.int/hia/about/glos/en/index 1.html). 